\title{
REACTOR ASPECTS OF COUNTERSTREAMING-ION TOKAMAK PLASMAS
}

\section{PLASMA PHYSICS LABORATORY}

\section{PRINCETON \\ UN IVER S I T Y PRINCETON, NEW JERSEY}




\section{DISCLAIMER}

This report was prepared as an account of work sponsored by an agency of the United States Government. Neither the United States Government nor any agency Thereof, nor any of their employees, makes any warranty, express or implied, or assumes any legal liability or responsibility for the accuracy, completeness, or usefulness of any information, apparatus, product, or process disclosed, or represents that its use would not infringe privately owned rights. Reference herein to any specific commercial product, process, or service by trade name, trademark, manufacturer, or otherwise does not necessarily constitute or imply its endorsement, recommendation, or favoring by the United States Government or any agency thereof. The views and opinions of authors expressed herein do not necessarily state or reflect those of the United States Government or any agency thereof. 


\section{DISCLAIMER}

Portions of this document may be illegible in electronic image products. Images are produced from the best available original document. 
CONTENTS

$\underline{\text { Page }}$

1. INTRODUCTION

2. POWER BALANCE AND FUSION REACTIVITY

2.1 Ion Velocity Distributions 5

2.2 Power Balance and Energy Confinement 9

2.3 Fusion Reactivity 12

2.4. Fusion Power Gain 13

2.5 Fusion Power Density 14

3. IMPLEMENTATION OF COUNTERSTREAMING OPERATION IN A TOKAMAK

3.1 Beam Trapping 16

3.2 Elimination of Decelerated Ions 20

3.3 Maintenance of Toroidal Current 22

3.4 Impurity Ions $\quad 24$

4. PLASMA PARAMETERS FOR REACTOR APPLICATIONS

4.1 Neutron Wall Loading 25

4.2 Choice of Injection Energy 27

4.3 Radiation Test Facility 29

4.4 Fusion-Fission Hybrid Reactors 31

4.5 Tritium Production 33

Table $1 \quad 35$

5. CONCLUSIONS $\quad$ Notice- Nopart was prepared as an account of work

REFERENCES i $\quad$ sponsored by the United States Government. Neither the United States nor the United States Energy Research and Development Administration, nor any of their employees, nor any of their contractors, their employees, nor any employees, makes any warranty, express or implied, or assumes any legal warranty, express aribility for the accuracy, completeness liability or responsibility for the accuraratus, product or process disclosed, or represents that its use would not infringe privately owned rights. 
REACTOR ASPECTS OF COUNTERSTREAMING-ION TOKAMAK PLASMAS

D. L. JASSBY

Plasma Physics Laboratory, Princeton University Princeton, N. J. 08540 U.S.A.

\section{ABSTRACT}

Toroidal DT plasmas in which the $\mathrm{D}$ and $\mathrm{T}$ ions make up two distinct, quasi-thermal velocity distributions, oppositely displaced in velocity along the magnetic axis., are discussed. Such counterstreaming distributions can be set up by introducing all ions by tangential injection of neutral beams, and by removing ions from the plasma shortly after they have decelerated to an energy $\tilde{<} 2 \mathrm{~T}_{e}$ by coulomb drag on the plasma electrons. A simple physical model for counterstreaming-ion operation is postulated, which allows one to deduce the ion velocity distributions and required energy and particle confinement times that are in good agreement with the results of previous Fokker-Planck calculations. The variations of fusion reactivity, pnwer gain, and power density with injection energy and electron temperature are presented. We consider the practical problems of implementing counterstreaming operation in a tokamak, such as charge-exchange losses, the prompt removal of cold.ions, and the effect of impurities.

Several properties of the counterstreaming system that make it advantageous for near-term reactor applications are (1) optimal performance at relatively low injection energy 
(40-60 keV), because of head-on nuclear collisions,

(2) small electron energy confinement time for $Q \sim 1$ (e.g., $\mathrm{n}_{\mathrm{e}} \mathrm{T}_{\mathrm{E}} \approx 2 \times 10^{12} \mathrm{~cm}^{-3}$ at $\mathrm{T}_{\mathrm{e}} \approx 3.5 \mathrm{keV}$ ), (3) refueling solely by the injected beams, and (4) maintenance of the plasma current by the beams. For realistic tokamak parameters, neutron wall loading is limited to $0.5 \mathrm{MW} / \mathrm{m}^{2}$ or less. Plasma parameters appropriate to radiation test reactors and fusion-fission hybrid reactors are discussed. 


\section{INTRODUCTION}

In thermal DT plasmas at moderate ion temperatures

$\left(T_{i} \approx 15 \mathrm{keV}\right)$, head-on collisions between $\mathrm{D}$ and $\mathrm{T}$ ions are ithe most effective in producing fusion energy. In this paper we consider a toroidal plasma in which the $\mathrm{D}$ and $\mathrm{T}$ ions are grouped in two distinct, quasi-thermal velocity distributions, oppositely displaced in velocity along the magnetic axis, as shown in Fig. 1 . The relative displacement velocity $\mathrm{v}_{r}$ is near the optimum value for generating fusion power, which occurs principally by nearly headon collisions between $\mathrm{D}$ and $\mathrm{T}$ ions of the counterstreaming distributions. Such velocity distributions can be set.up in a toroidal plasma container by introducing all ionsuby means of neutral beams injected parallel and anti-parallel to the toroidal magnetic field. The energetic ions slow down by Coulomb drag on the plasma electrons, and if decelerated ions are removed from the plasma in a time that is short compared with the fast-ion slowing-down time, virtually all plasma ions will be found in the two oppositely directed "beams". The electron temperature $\mathrm{T}_{\mathrm{e}}$ is maintained entirely by power flow from the fast ions. This eystem of space-charge neutralized, counterstreaming-ion distributions has been called a colliding-beam toroidal plasma, or CBT [1]. The Fokker-Planck analysis of Ref. [1] has shown that collisions among ions of the same beam cause significant diffusion of ion energy during thcir slowing-down history following injection, so that the ions form displaced Maxwellian-like distributions, as in Fig. 1. The beam "temperature" is sufficiently large so that the counterstreaming system is apparently stable to both electrostatic and electromagnetic velocity-space modes. 
The CBT system possesses certain advantages over thermonuclear and target-plasma (TCT) reactors. For the same fusion reactivity; injection voltages can be 3 to 4 times smaller than in the TCT, because head-on collisions increase the relative collision velocity. Somewhat larger Q-values can be attained, because of the reduction in cold-ion drag. For $T_{e}=2-6 \mathrm{keV}$, the electron confinement parameter $\mathrm{n}_{e} \tau_{E}$ is reduced by a factor of 2-4 in the CBT, to the range $0.5-5 \times 10^{12} \mathrm{~cm}^{-3} \mathrm{~s}$. Other properties advantageous for reactor applications are that. the plasma is fueled entirely by the beams, so that pellet injection technology is not required, and the plasma current can be maintained indefinitely by means of the injected beams.

Because $Q \sim 1$ operation is attainable at modest values of $T_{e}, n_{e} \tau^{\prime}$ and beam voltage, it seems appropriate to explore the practical use of CBT plasmas. While the ideal fusion gain in the CBT is limited to perhaps 5-10, there are several potential applications of fusion redclors for which $Q \ldots 1$ is quite adequate. These applications include fission-related activities such as fissile breeding and actinide burning [2], the large-scale production of tritium, and large-area neutron bombardment testing of wall materials and blankets. For such applicaliulns, fusion power density $P_{f}$ is of primary importance [3]. It io with an eye to these applications that this paper has evolved. (Another study will discuss means of maximizing $Q$ in a counterstreaming reactor, in order to enhance its viability as a sland-alone elcctrical power producer.) 
In Sec. 2 we develop a simple physical model that allows us to conveniently derive the ion velocity distributions and the energy and particle confinement times in CBT plasmas. These distributions are used to calculate $Q$ and $P_{f}$ over a range of injection voltages and $\mathrm{T}_{\mathrm{e}}$. While beam-driven, counterstreaming operation can in principle be applied to most toroidal configurations, in this study we shall direct our attention particularly to tokamak plasmas, since tokamak operation has proved to be the most successful to date. Section 3 discusses practical problems in the implementation of a counterstreaming-ion tokamak plasma, including the removal of decelerated ions, and the effects of charge exchange and impurities. The attainable neutron wall loading and illustrative reactor parameters for several applications are discussed in Sec. 4 .

\section{POWER BALANCE AND FUSION REACTIVITY}

\subsection{ION VELOCITY DISTRIBUTIONS}

In this paper we consider only. steady-state operation, although the CBT could also be operaled in a pulsed mode $[1]$; the latter mode seems somewhat unsuitable for reactor applications, however. Consider a steady-state counterstreaming-ion plasma into which energetic neutrals are injected parallel and anti-parallel to the magnetic axis. The neutrals are trapped by charge-exchange with ions travelling in the same direction, by impact ionization on oppositely travelling ions, and by electron ionization. The relative importance of the various trapping processes is discussed in Sec. 3.1 . 
The energetic ions are assumed to be confined until they decelerate to an energy $\mathrm{W} \sim 2 \mathrm{~T}$ e by Coulomb arag on the electrons. Ions with energy $W<2 \mathrm{~T}_{\mathrm{e}}$ are assumed to be lost at a rate $\tau^{-1} \sim \tau_{E}^{-1}$, where $\tau_{E}$ is the electron energy confinement time. It turns out that for $\mathrm{T}_{\mathrm{e}} \tilde{<} 10 \mathrm{keV}$, the slowing-down time of the fast ions is many times longer than $\tau_{e} \cdot$ Methods of removing cold ions from the plasma are discussed in sec.3.2. By means of a magnetic divertor, the inward flow rate of cold neutrals and ions from the wall can be kept small compared to the large rate of particle injection by the beams.

Let us consider the nature of the ion velocity distributions. The equilibration time among ions in the same beam is many times shorter than the slowing-down time on electrons. Interaction between ions in opposite beams is particularly important in causing angular scattering, and therefore a degree of isotropization. Thus one expects the ions in each beam to form a "thermal" distribution, with a mean velocity in the laboratory frame somewlid less than the injection velocity. Ref. [1] reports calculations of the ion distribution functions $f(v)$ with a multi-species, two-dimensional Fokker-Planck code that numerically solves the Fokker-Planck equation over a uniform mesh in velocity space. Must exlensive rcoulto are given in [4]. These fokker-Planck stsulls demonstratc that $f(v)$ does indeed resemble a displaced Maxwellian, with $T_{\perp}$ slightly larger than $T_{\|}$. The determination of most plasma parameters, as well as the reactor performance, is dependent on the accurate evaluation of $f(v)$. The numerical Fokker-Planck solutions are very expensive, however, and are not practical for extensive investigation of a wide range of parameters such as $\mathrm{T}_{\mathrm{e}^{\prime}} \mathrm{w}_{\mathrm{O}^{\prime}} \mathrm{n}_{\mathrm{D}} / \mathrm{n}_{\mathrm{T}}$. In 
the following, we describe a simple physical model that provides distribution functions that agree remarkably well with the known Fokker-Planck results. for $\mathrm{Z}=1$.

Consider a test ion, injected at energy $W_{0^{\prime}}$. that slows down by coulomb drag on plasma electrons, but has no interaction with other ions. The equation of motion of this ion is

$$
\frac{d w}{d t}=-\frac{\ln _{e}{ }^{\ln \Lambda_{e}}}{A_{i} T_{e}^{3 / 2}}\left(W-\frac{3}{2} T_{e}\right)
$$

Here $\mathrm{C}=1.06 \times 10^{-13}\left(\mathrm{~T}_{\mathrm{e}}, \mathrm{W}\right.$ in $\left.\mathrm{keV}\right)$, and $\mathrm{A}_{i}$ is the atomic mass of the ion. The average energy of this ion during its slowing-down time to an energy $2 \mathrm{~T}_{\mathrm{e}}$ is

$$
w_{s}=\frac{W_{o}-2 T_{e}+\frac{3}{2} T_{e} \log \left(\frac{W_{o}-\frac{3}{2} T_{e}}{\frac{1}{2} T_{e}}\right)}{\log \left(\frac{W_{o}-\frac{3}{2} T_{e}}{\frac{1}{2} T_{e}}\right)}
$$

In the case of continuous injection of noninteracting ions, each of which is removed immediately after deceleration to $\mathrm{W}=2 \mathrm{~T} \mathrm{e}^{\text {, }}$ the average energy of the distribution is also $\mathrm{W}_{\mathrm{s}}$. In practice, when $\mathrm{n}_{\mathrm{b}} \sim \mathrm{n}_{\mathrm{e}}$, where $\mathrm{n}_{\mathrm{b}}$ is the fast-ion density, the ion-ion collision time is very short compared to the slowing-down time $t_{s}$ on electrons, unless $T_{e}$ is very small. If $\tau_{12}$ is the energy exchange time between two inns with energies $w_{0}$ and $2 T_{e}$, respectively, we have

$$
\frac{\tau_{12}}{t_{s}} \approx \frac{1}{60}\left(\frac{W_{0}}{T_{e}}\right)^{3 / 2} \frac{1}{A_{i}^{1 / 2}} \frac{1}{\ln \left(\frac{W_{0}}{2 T_{e}}\right)} \sim \frac{1}{10}+\frac{1}{3}
$$

Ions with a smaller energy differential will interact even more rapidly, and some ions will be accelerated to energies well above the injection energy. One may reasonably propose that the ions 
form a displaced Maxwellian of temperature $\mathrm{T}_{\mathrm{b}}$ ' centered at $\mathrm{v}_{\mathrm{p}}=\left(2 \mathrm{~W}_{\mathrm{s}} / \mathrm{M}\right)^{\mathrm{l} / 2}$, as illustrated in Fig. 2. The normalized ion distribution function is

$$
f(\vec{v})=\left(\frac{M}{2 \pi T_{b}}\right)^{3 / 2} \exp \left[-\frac{M}{2 T_{b}}\left(\vec{v}-v_{p} \hat{\phi}\right)^{2}\right]
$$

where $\hat{\phi}$ is the unit vector along the magnetic axis. The average energy of this distribution is

$$
\overline{\mathrm{W}}=\frac{1}{2} \mathrm{Mv}_{\mathrm{r}}^{2}+\frac{3}{2} \mathrm{~T}_{\mathrm{b}}
$$

The determination of $\mathrm{T}_{\mathrm{b}}$ requires a further condition. Because of rapid ion-ion thermalization, the entire kinetic energy of the beam tends to be randomized. However, the directed motion is maintained by continuous ion injection at $w_{0}>w_{s}$ and by removal at $\mathrm{W} \lesssim 2 \mathrm{~T}_{\mathrm{e}}<\mathrm{W}_{\mathrm{s}}$. The injected energy is not entirely available for randomization among the lons, but also must be used to maintain the electron random motion (i.e., $\left.T_{e}\right)$. We postulate an equipartition of energy between the directed ion motion and the plasma thermal motion. That is,

$$
\frac{1}{2} \mathrm{Mv}_{\mathrm{p}}^{2}=\frac{3}{2} \mathrm{~T}_{\mathrm{e}}+\frac{3}{2} \mathrm{~T}_{\mathrm{b}}
$$

The equipartition postulate is justified by demonstrating that Eq. (4), wilh $W_{s}$ and $T_{b}$ determined from Eqs. (2) and (6) respectively, predicts plasma performance in agreement with the results of the previous Fokker-Planck calculations: (This postulate is also expected to hold. when $\mathrm{z}_{\text {eff }}>1$, but with $\mathrm{T}_{\mathrm{bl}_{2}}>\mathrm{T}_{\mathrm{b} \|}$.) 
Note that this model does not require interaction between ions of opposite beams. (In practice, angular scattering by ions of the opposing beam is important for the isotropization about $\mathrm{v}_{\mathrm{p}}$ ) In most of this work, the deuterons and tritons are injected with the same energies; since $W_{S}$ is independent of mass, the $\mathrm{D}$ and $\mathrm{T}$ distributions have the same temperature.

Figure 3 shows the dependence of $\mathrm{v}_{\mathrm{p}^{\prime}}, \mathrm{T}_{\mathrm{b}^{\prime}}$, and $\overline{\mathrm{W}}$ on $\mathrm{T}_{\mathrm{e}}$, using $\mathrm{W}_{\mathrm{O}}=60 \mathrm{keV}$ and Eqs. (2), (5), and (6).. These.results, particularly the temperature dependence of $\bar{W}$, are in good agreement wi.th the Fokker-Planck results $[1,4]$. In the latter calculations, "thermal" ions, that is, ions decelerated below $2 \mathrm{~T}_{\mathrm{e}}$, have a lifetime $\tau_{E}$. While the proportion $E_{T}$ of "thermal" ions may be as large as $30 \%$ for $\mathrm{T}_{\mathrm{e}} \approx 12 \mathrm{keV}$, the vast majority of these ions retain their direction of motion along the torvidal magnetic field.

For practical values of $\mathrm{W}_{\mathrm{o}}$ and $\mathrm{T}_{\mathrm{e}}$, the system of velocity distributions in the CBT is apparently stable to electrostatic and electromagnetic velocity-space modes $[1,5]$. If $v_{0}$ is the injection velocity, then $\left(v_{0} / v_{A l f v e n}\right)^{2} \approx B_{t}$, independent of $v_{0} \cdot$ since $\beta_{t} \ll 1$ in tokamak operation, Alfvén instabilities seem unlikely to occur. The stability of flnite-medium modes has not yet been investigated, but presumably a counterstreaming-ion plasma would be as susceptible as most toroidal plasmas to drift instabilities.

\subsection{POWER BALANCE AND ENERGY CONFINEMENT}

The electron temperature is maintained entirely by power flow from the fast ions, so that in practice $\mathrm{T}_{\mathrm{e}}$ and $\mathrm{n}_{\mathrm{e}}$ are determined by $\tau_{E}$ and the ion source strength $\mathrm{S} . \mathrm{T}_{\mathrm{e}}$ is found from the 
steady-state power balance relation

$$
\frac{3}{2} \frac{e^{T_{e}}}{\tau_{E}}=\frac{C n e^{\ln \Lambda} \Lambda_{e}}{T_{e}^{3 / 2}} \sum_{1,2} \frac{n_{i}\left(\bar{w}_{i}-3 / 2 T_{e}\right)}{A_{i}}
$$

Here $n_{i}$ is the density and $\bar{w}_{i}$ the average ion energy in each beam, as given by Eq. (5). In this work, we consider only the case $z=1$, so that $n_{e}=n_{1}+n_{2}$. The ion source strength is

$$
s_{i}=\frac{n_{i}}{\tau_{h i}}
$$

where $\tau_{h i}$ is the ion lifetime.

In the following we consider only cases where $\mathrm{n}_{1}=\mathrm{n}_{2}$ and $\mathrm{w}_{\mathrm{O} 1}=\mathrm{w}_{\mathrm{O} 2}$. (It should be noted, however, that for controlling plasma momentum and current, these conditions may have to be altered.) Defining $\tau_{h}^{-1}=\left(\tau_{h l}^{-1}+\tau_{h 2^{-1}}\right) / 2 ; \tau_{h} / \tau_{E}$ is given by

$$
\frac{3}{2} \frac{n_{c} T_{e}}{\tau_{E}}=\frac{n_{e}\left(W_{0}-\alpha T_{e}\right)}{\tau_{h}}
$$

where $\alpha \mathrm{T}_{\mathrm{e}} \sim 3 / 2 \mathrm{~T}_{\mathrm{e}}$ is the average energy of the ions leaving the plasma. Both $\tau_{E}$ and $\tau_{h}$ are Inversely proportional to $\mathrm{n}_{e}$, sxuept for the weakly varying in $\Lambda_{e}$ factor. Figure 4 shows $\tau_{h} / \tau_{E}$ as a function of $T_{\theta}$ and $w_{\theta}$ for $\alpha=2$. For most conditions, the ion lifetime must be many times $\tau_{E} \cdot$ This requirement seems compatible with observations on beam-injected tokamak plasmas [6], where in the absence of charge-exchange losses, the energetic ions remain in the plasma for their slowing-down time $\sim 10 \mathrm{~ms}$, while $\tau_{\mathrm{E}}$ is in the range 2-4 ms. In Ref. [7] it was shown that microinstabilities, such as drift instabilities, are relatively ineffective in causing 
diffusion of superthermal ions, so that one would expect fast ions to be lost prematurely only by faulty magnetic surfaces, or by charge-exchange.

In analyzing CBT reactor performance, it is often most convenient to choose $\mathrm{n}_{e}$ and $\mathrm{T}_{\mathrm{e}}$, and to calculate the corresponding value of $n_{e} \dot{\tau}_{E}$ from Eq. (7). Figure 5 shows $n_{e} \tau_{E}$ as a function of $\mathrm{T}_{\mathrm{e}}$ and $\mathrm{w}_{\mathrm{o}} \cdot$ Evidently, the predicted $\mathrm{n}_{\mathrm{e}} \tau_{E}$ for $\mathrm{w}_{\mathrm{o}}=60 \mathrm{keV}$. is in excellent agreement with the values obtained from the numerical Fokker-Planck solutions, thus lending support to the model of Sect. 2.1. Also shown in Fig. 5 is $n_{e} \tau_{E}$ for a TCT plasma with $\mathrm{w}_{\mathrm{O}}=200 \mathrm{keV}$, the same relative collision energy as in the 60-keV CBT: case. In the TCT, $\mathrm{n}_{e} \tau_{\mathrm{E}}$ may have a wide rainge of values for a given $\mathrm{T}_{\mathrm{e}}$, depending on the choice of $\mathrm{n}_{\mathrm{b}} / \mathrm{n}_{\mathrm{e}}$; the curve in Fig. 5 is calculated for the case of maximum $P_{f}[3]$. In the CBT, on the other hand, $\mathrm{n}_{b} / \mathrm{n}_{e} \approx 1$, so that there is a unique value of $\mathrm{n}_{e} \tau_{E}$ for each $T_{e}\left(\right.$ at constant $\left.W_{o}\right)$. At low $T_{e}$ this value can be many times smaller than in the TCT, where many more particles must be heated by a given population of energetic ions. But at large 'T $e^{\prime}$ the fast-ion slowing-down time is much longer in the r.BT, so that $\mathrm{n}_{e}{ }^{\tau} \mathrm{E}$ values tend to be comparable.

A useful quantity in discussing beam-maintained plasmas is $\bar{\Gamma}$, defined as

$$
\bar{\Gamma}=\frac{\text { superthermal-ion encrgy density }}{\text { thermal-plasma energy density }}=\frac{n_{b}\left(1-f_{T}\right) \bar{W}}{\frac{3}{2} n_{e}\left(1+f_{T}\right) T_{e}}
$$

In typical operation of a target-plasma reactor, $\Gamma \approx 1$ [3]; in the CBT, $\bar{\Gamma} \approx \frac{2}{3}\left(\bar{W} / T_{e}\right) \gg 1$, and $\bar{l}$ is essentially the ratio of the ion pressure to the electron pressure. 


\section{3 FUSION REACTIVITY}

In this section we calculate the fusion reactivity of the system of counterstreaming $\mathrm{D}$ and $\mathrm{T}$ ions. The reactivity is

$$
\langle\sigma v\rangle_{c}=\frac{\iint d \vec{v}_{1} d \vec{v}_{2} \sigma\left(v_{12}\right) v_{12} f_{1}\left(\vec{v}_{1}\right) f_{2}\left(\vec{v}_{2}\right)}{\iint d \vec{v}_{1} d \vec{v}_{2} f_{1}\left(\vec{v}_{1}\right) f_{2}\left(\vec{v}_{2}\right)}
$$

where $v_{12}=\left|\vec{v}_{1}-\vec{v}_{2}\right|, f_{1}$ and $E_{2}$ are given by $E q \cdot(4)$, and $\sigma\left(v_{12}\right)$ is the fusion cross-section for $D$ and $T$ nuclei with relative collision velocity $\mathrm{v}_{12}$. We consider only the case of equal injection energies for $D$ and $T$. Then as discussed in Sect. 2.1, each distribution has the same $\mathrm{T}_{\mathrm{b}^{\prime}}$, while $\mathrm{v}_{\mathrm{PT}}=-\sqrt{\frac{2}{3}} \mathrm{v}_{\mathrm{pD}} \cdot \mathrm{Th}$. six-fold integrals in Eq.(1.1) can be reduced to single integrals by transforming the variables of integration to $\vec{v}_{12}=\vec{v}_{1}-\vec{v}_{2}$ and $\vec{V}=\left(M_{1} \vec{v}_{1}+M_{2} \vec{v}_{2}\right) /\left(M_{1}+M_{2}\right)$, where $\vec{M}_{1}$ and $M_{2}$ are the masses of the two ion species. The result is

$$
\langle\sigma\rangle_{c}=\frac{\int_{0}^{v_{\max }} d v_{12} \sigma\left(v_{12}\right) v_{12}}{\int_{0}^{v_{\max }} d v_{12} v_{12}\left(e^{\left.c_{1} v_{12}-e^{-c_{1} v_{12}}\right) e^{-\mu v_{12} / 2 T_{b}}}\right.}
$$

Here $\mu=\mathrm{M}_{1} \mathrm{M}_{2} /\left(\mathrm{M}_{1}+\mathrm{M}_{2}\right), \mathrm{C}_{1}=\left(1+\sqrt{\frac{2}{3}}\right) \mu \mathrm{v}_{\mathrm{pD}} / \mathrm{T}_{\mathrm{b}}, \mathrm{v}_{\max } \rightarrow \mathrm{v}_{\mathrm{pD}}|+| \mathrm{v}_{\mathrm{pT}} \mid$.

The integrals in Eq. (12) have been evaluated numerically, using $\sigma(v)$ from Ref. [8]. Figure 6 shows $\langle\sigma v\rangle_{c}$ as a function of $\dot{v}_{r}=\left|v_{p_{D}}\right|+\left|v_{p T}\right|$, the relative displacement of the peaks of $f_{1}\left(\vec{v}_{1}\right)$ and $\mathrm{f}_{2}\left(\overrightarrow{\mathrm{v}}_{2}\right)$ [Fig. 1]. Several points are worth noting:

(1) For $v_{r}=0,\langle\sigma v\rangle_{c}$ is the usual fusion reactivity of an isotropic Maxwellian DT plasma. 
(2) As $\mathrm{T}_{\mathrm{b}} \rightarrow 0$, the peak value of $\langle\sigma v\rangle_{\mathrm{C}}$ approaches the maximum value for a beam-target system. This value is $1.67 \times 10^{-15}$ $\mathrm{cm}^{3} / \mathrm{s}$ for $\mathrm{w}=128 \mathrm{keV}$.

(3) For any. $T_{b},\langle\sigma v\rangle_{c}$ can be larger than the maximum reactivity of a thermonuclear plasma, viz. $8.8 \times 10^{-16} \mathrm{~cm}^{3} / \mathrm{s}$ at $\mathrm{T}_{\mathrm{i}}=60 \mathrm{keV}$.

Thus in the counterstreaming mode, a low temperature distribution of ions may have a very large fusion reactivity. However, the distribution must be maintained by continuous beam injection, so that the system has only a moderate $Q$, as shown in the next section.

\subsection{FUSION POWER GAIN}

In steady-state operation, the fusion power gain is $Q=P_{f} / P_{b}$, where $P_{f}$ is the fusion power density and $P_{b}$ is the injected power density:

$$
P_{f}=n_{D} n_{T}\langle\sigma v\rangle_{C} E_{f}=\frac{1}{4} n_{e}{ }^{2}\langle\sigma v\rangle_{C} E_{f},
$$

where $E_{f}=17,600 \mathrm{kev}$, and $\bar{n}_{D} \equiv n_{T}=\frac{1}{2} n_{e}$;

$$
P_{b}=\frac{w_{O D} n_{D}}{\tau_{h D}}+\frac{w_{O T} n_{T}}{\tau_{h T}}=\frac{w_{O} n_{e}}{\tau_{h}},
$$

where $\tau_{h}$ is defined as in Eq. (9).

$$
Q=\frac{1}{\sigma}\langle\sigma v\rangle_{c} \frac{E_{f}}{W_{o}} \frac{n_{e} \tau_{E}\left(W_{o}-\alpha T_{e}\right)}{T_{e}}
$$


$\mathrm{n}_{\mathrm{e}^{\tau} \mathrm{E}}$ and $\langle\sigma v\rangle_{\mathrm{c}}$ are found from Eqs. (7) and (12), respectively. Figure 7 compares the predicted temperature dependence of $Q$ with previous Fokker-Planck results for $\mathrm{W}_{\mathrm{OD}}=60 \mathrm{keV}$ and $\mathrm{W}_{\mathrm{OT}}=40 \mathrm{keV}[1]$. The agreement is everywhere better than 10\%, again lending support to the model of sect. 2.1. Note also the large increase in $Q$ over the TCT reactor [9], in which the cold target ions exert appreciable drag on the relatively few beam ions.

Fiqure 8 shows the dependence of $Q$ on injection energy and electron temperature. Evidently, Q is rather insensitive to $\mathrm{W}_{\mathrm{o}}$; for each $\mathrm{T}_{\mathrm{e}}$ there is a broad maximum in the range $\mathrm{w}_{\mathrm{O}}=0$ 40-60 kov, corresponding to a relative collision energy of $130-200 \mathrm{keV}$ at injection. For $W_{0}>3 / 2 \mathrm{~T}_{e}$, and ignoring the variation in $W_{s}$ with

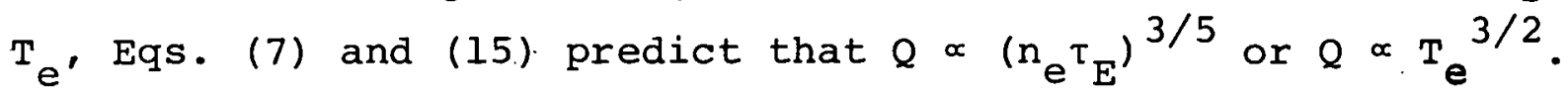
(The Q-curves are not plotted for $\mathrm{W}_{\mathrm{O}} \leq 4 \mathrm{~T}_{\mathrm{e}}$, since for these conditions, the calculation of $\mathrm{w}_{\mathrm{s}}$ is somewhat sensitive to. the "cutoff" $\mathrm{W}=2 \mathrm{~T}_{\mathrm{e}}$, which is used in the derivation of Eq. (2).)

In this work we assume that alpha particles from fusion reactions are not confined. Retention of fusion alphas does not significantly increase $Q$, and finite-alpha pressure reduces the allowable beam-ion density, thereby lowering $\mathrm{P}_{f}$.

\subsection{FUSION POWER DENSITY}

It is instructive to compare sem1-quantitatively the permissible values of $\mathrm{n}_{e}$ and $\mathrm{P}_{f}$ in the counterstreaming and target-plasma reactors, for the same values of $\mathrm{T}_{\mathrm{e}}$ and total plasma pressure $\mathrm{p}$. In the TCT, with $\mathrm{T}_{\mathrm{e}}=\mathrm{T}_{i}$, we have 


$$
\mathrm{p}=2\left(\mathrm{n}_{\mathrm{e}}\right) \text { TCT } \mathrm{T}_{\mathrm{e}}(1+\bar{\Gamma}) \approx 4\left(\overline{\mathrm{n}}_{\mathrm{e}}\right) \text { TCT } \mathrm{T}_{\mathrm{e}}
$$

where $\bar{\Gamma} \approx 1$ is near the optimal value for maximizing $\mathrm{P}_{f}[3]$. In the CBT,

$$
\mathrm{p}=\left(\mathrm{n}_{\mathrm{e}}\right)_{\mathrm{CBT}}\left(\mathrm{T}_{\mathrm{e}}+\frac{2}{3} \overline{\mathrm{W}}\right) \approx \frac{2}{3} \overline{\mathrm{W}}\left(\mathrm{n}_{\mathrm{e}}\right)_{\mathrm{CBT}}
$$

Here we have noted that superthermal ions produce an isotropic pressure, even if these ions have a streaming motion along $B_{t}[10]$. Combining Eqs. (16) and (17), we have

$$
\frac{\left(\mathrm{n}_{\mathrm{e}}\right)_{\mathrm{CBT}}}{\left(\mathrm{n}_{\mathrm{e}}\right)_{\mathrm{TCT}}} \approx \frac{6 \mathrm{~T}}{\mathrm{e}}=\frac{1}{\overline{\mathrm{W}}_{\mathrm{i}}} \rightarrow 1
$$

(See, for example, Fig. 3c.) In the TCT, typically $\mathrm{n}_{\mathrm{D}} \approx \frac{1}{8} \mathrm{n}_{\mathrm{e}^{\prime}}$ while $\langle\sigma \mathrm{v}\rangle_{\mathrm{C}} \approx\langle\sigma \mathrm{v}\rangle_{\mathrm{TCT}}$. Therefore

$$
\frac{\left(\mathrm{P}_{\mathrm{f}}\right)_{\mathrm{CBT}}}{\left(\mathrm{P}_{\mathrm{f}}\right)_{\mathrm{TCT}}}=\frac{1 / 4\left(\mathrm{n}_{\mathrm{e}}\right)_{\mathrm{CBT}}^{2}\langle\mathrm{\sigma v}\rangle_{\mathrm{C}}}{\left(\mathrm{n}_{\mathrm{D}} \mathrm{n}_{\mathrm{T}}\right)_{\mathrm{TCT}}\langle\sigma \mathrm{V}\rangle_{\mathrm{TCT}}} \approx \frac{1}{2}+2
$$

Thus both $\mathrm{n}_{\mathrm{e}}$ and $\mathrm{P}_{f}$ are comparable in the two modes of operation. The pressure limitation of a tokamak plasma is given by the MHD equilibrium condition on the poloidal beta:

$$
\beta_{p}=\frac{8 \pi \bar{p}}{B_{p}^{2}}=\frac{8 \pi \bar{p} q^{2} A^{2}}{B_{t}^{2}} \leq A
$$

where $A=R / a$ is the aspect ratio, and $q$ is the safety factor at the limiter. In this section we use the illustrative values $B_{t}=50 \mathrm{kG}, q=2.5, A=5.0, B_{p}=3.0$, so that $\bar{p}=0.19 \mathrm{~J} / \mathrm{cm}^{3}$. 
Then $\mathrm{P}_{\mathrm{f}}$ is found from Eqs. (12) and (13), using $\mathrm{n}_{\mathrm{D}}=\mathrm{n}_{\mathrm{T}}=\frac{1}{2} \mathrm{n}_{\mathrm{e}}=$ $\frac{1}{2} \mathrm{p} /\left(\mathrm{T}_{\mathrm{e}}+\frac{2}{3} \overline{\mathrm{W}}\right) \cdot$ Figure 9 shows the dependence of $\mathrm{P}_{f}$ on $\mathrm{W}_{\mathrm{O}}$ and $\mathrm{T}_{\mathrm{e}} \cdot \mathrm{P}_{\mathrm{f}}$ is maximum at the smallest $\mathrm{T}_{\mathrm{e}}$ and $\mathrm{W}_{\mathrm{o}^{\prime}}$ since for constant pressure, larger $\mathrm{n}_{e}$ is permitted at smaller electron and beam energies. The minimum practical $w_{0}$ is determined by the difficulty of the neutral beams in penetrating the plasma (Sec. 3.1), while the minimum desirable $\mathrm{T}_{\mathrm{e}}$ is determined by the minimum Q-value required (cf. Fig. 8).

Figure 10 shows $Q$ vs $P_{f}$ lur congtant $W_{O}$ and $P$, Fiach point on a constant- $W_{0}$ curve corresponda to a partiniliar value of $n_{e}{ }^{\tau}$ ! and therefore a definite $\mathrm{T}_{\mathrm{e}}$ given by Eq. (7). There is necessarily a trade-off between $P_{f}$ and $Q$, the largest values of $P_{f}$ being obtained at the smallest $n_{e} \tau_{E}$ and $T_{e}$. The large-n $n_{e} \tau_{E}$ region is the most appropriate for stand-alone" power producers, while the low $-\mathrm{n}_{\mathrm{e}}{ }^{\mathrm{E}} \mathrm{E}$ region is the most attractive for maximizing neutron production. In the latter operating regime, the throughput of plasma energy is extremely large, and Lhe most important conflnement role of the tokamak is the confinement of the injected ions during their long slowing-down period (cf. Fig. 4).

\section{IMPLEMENTATION OF COUNTERSTREAMING UFERATION IN A TOIRAMAK}

\subsection{BEAM TRĀPPING}

A target plasma is required to initiate CBT operation. This target plasma can be a low-temperature tokamak plasma ( $\mathrm{T}_{\mathrm{e}} \sim \mathrm{I} \mathrm{keV}$ ) of moderate density $\left(\mathrm{n}_{e} \sim 2 \times 10^{13} \mathrm{~cm}^{-3}\right)$, set up in the usual way by gas filling and ohmic heating. Beam-injected neutrals are 
trapped by charge-exchange and ionization by plasma ions and electrons. Once beam injection has begun, the divertor coils are energized, so that recycling of outwardly diffusing ions is minimized; essentially all further particle input to the plasma comes from the beams.

After injection for several slowing-down times, $\mathrm{T}_{\mathrm{e}}$ reaches its final value, and the ion population is dominated by energetic ions. In the steady state, injected neutrals are trapped by the ions in the counterstreaming distributions, and by electron ionization. The rate coefficients shown in Fig. 1l, taken from Ref. [11], are required for calculating the trapping length. Consider a deuterium atom $\left(D^{\circ}\right)$ injected tangentially with velocity $v_{0}$ into the CBT plasma. The relative collision energy $U$ between the $D^{\circ}$ and $D^{+}$ions is very small (e.g., $U \approx 7 \mathrm{keV}$ for the $\mathrm{T}_{\mathrm{e}}=5 \mathrm{keV}$ case of Fig. 3), while $\mathrm{U}$ for collisions between the $\mathrm{D}^{\circ}$ and $\mathrm{T}^{+}$ions is very large $(\mathrm{U} \approx 140 \mathrm{keV}$ for the same case). Approximately half the neutrals are trapped by charge-exchange with ions of the same species, and the other half by impact ionization on ions of the other species, and by electron ionization. The penetration length is given by

$$
\begin{aligned}
& \lambda_{t}=v_{0}\left[n_{1}\left\langle\dot{\sigma}_{c x}\left(u_{11}\right) u_{11}\right\rangle+n_{2}\left\langle\sigma_{c x}\left(u_{12}\right) u_{12}\right\rangle\right. \\
& \left.+n_{1}\left\langle\sigma_{I}\left(u_{11}\right) u_{11}\right\rangle+n_{2}\left\langle\sigma_{I}\left(u_{12}\right) u_{12}\right\rangle+n_{e}\left\langle\sigma_{e} v_{e}\right\rangle\right]^{-1}
\end{aligned}
$$

where $u_{11}=\left|\vec{v}_{0}-\vec{v}_{1}\right|$ and $u_{12}=\left|\vec{v}_{0}-\vec{v}_{2}\right|$ are the relative velocities between the fast neutral and ions of the two species of densities 
$\mathrm{n}_{1}$ and $\mathrm{n}_{2}, \sigma_{\mathrm{Cx}}$ and $\sigma_{I}$ are the charge-exchange and impact-ionization cross-sections, respectively, and $\left\langle\sigma_{e} v_{e}\right\rangle$ is the electron ionization rate, averaged over a Maxwellian electron velocity distribution. For each charge-exchange or impact-ionization process,

$$
\langle\sigma \vec{v}\rangle=\frac{\int d \vec{v}_{i} \sigma(u) u\left(f_{i}\left(\vec{v}_{i}\right)\right.}{\int d \vec{v}_{i} f_{i}\left(\vec{v}_{i}\right)}
$$

where $f_{i}\left(\vec{v}_{i}\right)$ is given by Eq. (4). The three-fold integrals are reduced to a single integral by the Liangformation $\vec{u}=\vec{v}_{0}-\vec{v}_{1}$. The result is

$$
\langle\sigma v\rangle=\frac{\int_{0}^{u_{\max }} d u \sigma(u) u^{2}}{\int_{0}^{u_{\max }} d u u\left(e^{C_{3} u}-e^{-C_{3} u}\right) e^{-M_{i} u^{2} / 2 T_{b}}}
$$

where $C_{3}=M_{i}\left(v_{p i}-v_{o}\right) / T_{b}, v_{p i}=\left(2 W_{s} / M_{i}\right)^{1 / 2}$, and $u_{\max } \gg\left|v_{0}\right|+\left|v_{p i}\right|$.

Figure $12(a)$ shows $\lambda_{t}$ for $D^{\circ}$ as a function of neutral energy, with $\mathrm{n}_{e}=5 \times 10^{13} \mathrm{~cm}^{-3}$ and $\mathrm{I}^{\mathrm{H}}=4.0 \mathrm{keV}$. The dependence of $\lambda_{t}$ on $\mathrm{T}_{e}$ enters through $\left\langle\sigma_{e} v_{e}\right\rangle$, and through the variation of $f_{i}\left(\vec{v}_{i}\right)$ with $\mathrm{T}_{e}$. In this work, $\mathrm{W}_{\mathrm{OT}}=\mathrm{W}_{\mathrm{OD}}$, so that $\lambda_{t}$ for $\mathrm{T}^{\circ}$ is only $81 \%$ of that for $D^{0}$. This difference is generally not significant, however, since in steady-state operation, the ions will be distributed over most of the radial profile, and in any event, one can inject $D$ and $T$ beams along chords that are displaced by different amounts from the magnetic axis. (Actually, the difference in $\lambda_{t}{ }^{-}$ values could be compensated in a tokamak by injecting $T^{\circ}$ in the 
direction of the current, $\mathrm{J}$, and injecting $D^{\circ}$ in the opposite direction. Then the drift surfaces of the resulting $\mathrm{D}^{+}$shift outward, while those of the $\mathrm{T}^{+}$shift inward [12].)

Figure $12(\mathrm{a})$ also shows $\mathrm{R}_{\mathrm{cx} \mathbf{x}^{\prime}}^{0}$ the probability of the injected neutral being trapped by charge-exchange. The average energy of the secondary neutral is in the range $0.6-0.9 \bar{w}$, dependirig on $\mathrm{W}_{\mathrm{OD}}$ and $\mathrm{T}_{\mathrm{e}}$. This neutral will be travelling nearly parallel to the magnetic axis, and will undergo charge-exchange or ionization before escaping. Successive generations of neutrals are formed in this way, until finally ionization occurs, or the neutral escapes. The trapping process thus leads immediately to a certain loss of energy.

The charge-exchange energy loss can be estimated with the aid of Fig. 13. For illustrative purposes, we consider a plasma of aspect ratio $\mathrm{A}=5.0$, uniform $\mathrm{n}_{e}$, radius $\mathrm{a}=\lambda_{t}, \mathrm{~T}_{e}=4 \mathrm{keV}$, and $\mathrm{w}_{\mathrm{OD}}=60 \mathrm{kev}$. The injection trajectory is a chord lying slightly inside the magnetic axis, so that penetration to the axis is adequate even when $\lambda_{t} \approx a$ [i2]. The total path length in the plasma is $L \approx 2\left(2 R_{O} a+a^{2}\right)^{1 / 2}=6.65 a$. For $W_{O D}=60 \mathrm{sev}$, the average energy of the charge-exchange neutral is $W_{n}=34 \mathrm{kev}$. As shown in Fig. 12(b), this neutral in turn has a mean-free-path for a charge-exchange or ionization collision of $\lambda_{n}=0.75 \lambda_{t}$ ' with $R_{C x}^{\prime}=0.64$. Suppose that all succeeding neutrals have cnergy $W_{n}$, and that the Nth generation neutral is lost from the plasma. Then the fraction of injected energy lost by chargeexchange is

$$
F_{C X}=\frac{W_{n}}{W_{O}} R_{C x}^{O}\left(R_{C X}^{\prime}\right)^{N-1}
$$


Since $L=6.65 a \approx \lambda_{t}+7 \lambda_{n}, N$ could be as large as 8 . However, the injected neutrals and plasma ions have velocities that are not exactly parallel to the magnetic axis, so that $N=4$ or 5 seems reasonable, for which $F_{C x}$ is 0.09 and 0.06 respectively. Both $Q$ and $P_{f}$ are reduced by approximately the factor $1-F_{\text {Cx }}$. According to our basic postulates, neutrals enter the plasma only by beam injection (recycling is not permitted), so that the above analysis accounts completely for charge-exchange 1oss. This process reduces $Q$ and $\mu_{f}$ by less than $10 \%$. While the charge-exchange loss is smaller at larger $W_{O}$, both $Q$ and $P_{f}$ are inherently reduced for $W_{O}>60 \mathrm{keV}$ (cf. Figs. 8 and 9).

\subsection{ELIMINATION OF DECELERATED IONS}

In order to maintain ion velocity distributions such as shown in Fig. 2, two conditions must be met:

(1) The rate of recycling of cold ions and neutrals must be small compared with the rate of jarticle input by the neutral beams. This condition can probably be met with the use of a poloidal magnetic divertor [13]. Such a divertor is required also for minimizing bombarament of the vacuum wall by outgoing particles. In any event, the rate of ion energy outflow $\left(\sim 3 / 2 \mathrm{n}_{\mathrm{e}} \mathrm{T}_{\mathrm{e}} / \tau_{\mathrm{h}}\right)$ is less than the plasma power throughput by the ratio $\tau_{E} / \tau_{h} \ll 1$. Practically all the injected energy is lost through the electron channel.

(2) Decelerated ions (ions with $\mathrm{w} \div 2 \mathrm{~T}$ ) must be removed from the plasma in a time $\tau$ that is short compared with their slowingdown time; i.e., $\tau \ll \tau_{h}$. The results of Ref. [4] have shown that $Q$ is rather insensitive to the exact value of $\tau / \tau_{h}$, when $\tau \sim \tau_{E}$. 
There are three processes that appear effective for the rapid removal of decelerated ions:

(i) Charge-exchange of injected neutrals. In the example of Sec. 3.1, the ratio of the particle loss rate by charge-exchange to the particle injection rate is $F_{c x} W_{0} / W_{n} \sim 1 / 8$. While the average energy of the escaping neutrals is relatively large, an appreciable fraction of these neutrals have low energy.

(ii) Instability-induced diffusion. The temperature of a practical CBT plasma will be sufficiently high so that electrons and ions will lie in the collișionless "banana" regime, and trapped-particle instabilities can be expected to exist [14]. While these instabilities apparently cause negligible radial diffusion of energetic ions, because of the short wave-particle correlation times [7], they should be rather effective in the elimination of thermal ions and electrons. Collective arift-type microinstabilities cause comparable loss rates of particles and energy, so that if they are chiefly responsible for the electron energy loss rate $\tau_{E}^{-1}$, one expects that $\tau^{-1} \sim \tau_{E}^{-1}$.

It is desirable to operate with a large "peaking factor" of the injected beams [12], so that there will be a gradual outward diffusion of the fast ions during their slowing-down period. The colder ions, which are susceptible to instability-induced diffusion, will have a relatively short diffusion length before they are eaptured by the poloidal divertor.

(iii) Toroidal magnetic field ripple. Ripple in the toroidal magnetic field can lead to enhanced diffusion of thermal plasma particles [15]. But ripple has the undesirable effect of enhancing 
deceleration of the counterstreaming velocities in the laboratory. frame [16], and is also effective in eliminating energetic ions trapped in banana orbits. Field ripple is generally small in a tokamak $(e . g,, \delta B / B \ll 1 \%$ near the magnetic axis), but it can be made rather large in the outer region of the plasma. Rippleinduced loss would be most beneficial in the case of large "peaking factors," so that, as explained above, only colder ions would find themselves in the region of appreciable ripple.

All three of these loss processes can be made to act in concert, so that the prompt removal of decelerated ions does seem feasible. Nevertheless, this requirement seems likely to be the most important difficulty facing successful implementation of the counterstreaming-ion plasma.

\subsection{MAINTENANCE OF TOROIDAL CURRENT}

The counterstreaming-ion distributions have currents associated with them, but it is easily shown that when $z_{\text {eff }}=1$, the total plasma current is zero unless an external electric field $\overrightarrow{\mathrm{E}}$ is applied. We suppose that the deuterons are injected oppositely to $\vec{E}$, so that the deuteron streaming velocity is in the same direction as the electron drift velocity. The șleady-slale electron momentum-balance equation is

$$
n_{e}^{e E}+K n_{D} n_{e}\left(v_{D}-v_{e}\right)-K n_{T} n_{e}\left(v_{e}+v_{T}\right)=0
$$

where $\mathrm{K}=$ constant $\times \ln \Lambda_{\mathrm{e}} / \mathrm{T}_{\mathrm{e}} \mathrm{e}^{3 / 2}$ and $\mathrm{v}_{\mathrm{e}^{\prime}}, \mathrm{v}_{\mathrm{D}^{\prime}}, \mathrm{v}_{\mathrm{T}}$ are the magnitudes of the average streaming velocities of the electrons, deuterons, and tritons, respectively. From Eq. (25), we have 


$$
v_{e}=\frac{1}{n_{D}+n_{T}}\left(\frac{e E}{K}+n_{D} v_{D}-n_{T} v_{T}\right)
$$

The plasma current density is

$$
\dot{J}=-e\left(n_{e} v_{e}-n_{D} v_{D}+n_{T} v_{T}\right)
$$

If $z_{\text {eff }}=1$, then $n_{e}=n_{D}+n_{T}$, and

$$
J=-\frac{e^{2} E}{K}
$$

If the toroidal ion current happens to be unbalanced, the electron velocity distribution shifts so that momentum balance of electrons is always maintained, and net current can be driven only by an external field.

(While the electric field tends to accelerate the tritons, solution of the momentum balance equations for the ions shows that this effect is overwhelmed by the electron drag on the tritons, so that continuous injection is required to maintain the triton drift velocity [17].)

If the plasma has an impurity population, or if a significant fraction of the electrons are trapped in banana orbits or in toroidal field ripple, then $z_{\text {eff }}>1$, and a toroidal current can be maintained even when $E=0$ [17]. (A similar situation can be established in a beam-heated thermal reactor [18].) Thus the counterstreaming-ion tokamak plasma can be operated for extremely long pulse times, with the volt-sec requirement of the 
transformer core determined only by current startup. Since the refueling of the plasma is carried out solely by the injected beams, it appears that virtually steady-state operation is attainable.

The ohmic power dissipation $\mathrm{P}_{\mathrm{OH}}$ for typical conditions is in the range $0.01-0.03 \mathrm{~W} / \mathrm{cm}^{3}$; so that $\mathrm{P}_{\mathrm{OH}} / \mathrm{P}_{\mathrm{b}} \sim 10^{-2}-10^{-1}$. Essentially all the power input to the electrons comes from Coulomb energy transfer from the fast iuns.

\subsection{IMPURITY IONS}

The principal effect of an impurity population in the CBT is enhanced pitch-angle scattering, which undermines the advantage of head-on collisions. A second deleterious effect is the additional coulomb drag on the energetic ions by the impurity ions and their neutralizing electrons. For high-z impurities, the second ettect is much less dalldyiny llian the first. Proliminary results in Ref. [4] demonstrated that for $W_{0}=60 \mathrm{keV}, T_{e}=5 \mathrm{keV}$, and iron impurity, $Q$ is reduced by $33 \%$ and $46 \%$ for $Z_{\text {eff }}=2$ and 3 , respectively. Pitch-angle scattering can be moderated by going to higher injection energy, but again this leads to some loss in $Q$ and $P_{f}$ even when $Z_{\text {eff }}=1$.

Radiation losses are enhanced by a high-z impurity population, but increased: radiation does not significantly affect $Q$ or $P_{f}$ in a purely beam-driven reactor [3], and can even be desirable for regulating $\tau_{E}$. The penetration length of neutral beams is reduced in the presence of impurities, since the rate coefficient for impact ionization by oppositely travelling ions is proportional to $Z_{\text {eff }}[19]$. This effect has also the beneficial result of reducing the charge-exchange energy loss associated with trapping by the co-streaming ions. 
While the impurity population can presumably be minimized by means of a poloidal divertor, which is required in any event (Sec. 3.2), it is relevant to note that $z_{\text {eff }} \approx 1$ plasmas (after correction for electron trapping) have been attained in both the Alcator [20] and ATC [21] tokamaks, without the use of a divertor. In each case, however, the plasma energy density was much smaller than we envisage here.

\section{PLASMA PARAMETERS FOR REACTOR APPLICATIONS}

\subsection{NEUTRON WALL LOADING}

The confinement requirements of electrons and ions in CBT plasmas are sufficiently lenient, at least at low $T_{e}$ that one can conceive of $Q \gtrsim 1$ reactors with thermal power outputs in the 5-50 MW range. But very large power output may be required for economic reasons, and a large neutron wall loading may be demanded for such applications as nuclear transmutation or materials testing. This section is particularly concerned with the problem of attaining large wall loading.

Given $T_{e}$ and $W_{o}=W_{O D}=W_{o ̈}$, the fusion power density for a plasma of arbitrary cross-section is

$$
P_{f}=4.34 \times 10^{-4} P_{f_{O}}\left(\frac{B_{t}}{q A}\right)^{4} \beta_{p}^{2} s^{4}
$$

where $\mathrm{P}_{\text {fo }}$ is the value given in Fig. 9, and $\mathrm{S}=$ plasma circum-

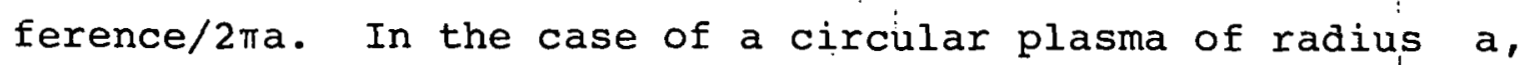
with uniform $\mathrm{n}_{\mathrm{e}}$ and $\mathrm{T}_{\mathrm{e}}$, and a circular vacuum chamber of radius 
$a_{w}$, the neutron wall loading is

$$
W L=0.40 P_{f}\left(\frac{a}{a_{w}}\right) a
$$

If $W_{0}$ is fixed, the plasma radius cannot be arbitrarily increased in order to increase WL, because of the limited penetration of the neutral beams. Figure 14 shows WI as a function of $W_{0}$ with the plasma pressure tixèd. Fur eduli $W_{O}$, the plasma radius is $a=\lambda_{t}$ so that penetration is always satisfactory [12]: We take $a_{w} / a=1.3$, which allows adequate space for the divertor scrapeoff region. If $T_{e}$ is small, WL attains its maximum value at $\mathrm{W}_{\mathrm{O}} \approx 100 \mathrm{keV}$, while if $\mathrm{T}_{\mathrm{e}}$ is large, $\mathrm{WL}$ is maximum at $\mathrm{W}_{\mathrm{o}} \approx 60 \mathrm{keV}$. These plasmas are all relatively small, with a $<100 \mathrm{~cm}$. Increasing the plasma size beyond $a \approx 100 \mathrm{~cm}$ (and therefore increasing $\mathrm{w}_{0}$ ) results in a larger power output, bul the wall loading is reduced. It should also be kept in mind that the efficiency of neutral beam production tends to decrease at larger beam energies.

The parameters on the right side of Eq. (29) may be varied to increase $P_{f}$, but such variation generally implies an increase in $n_{e}$, so that $\lambda_{t}$ and a must be reduced. Thus substantial changes in WL from the values shown in Fig. 14 are difficult to achieve. It appears very unlikely that a wall loading greater than $0.50 \mathrm{MW} / \mathrm{m}^{2}$ can be attained.

In practice, one operates at the largest $B_{t}$ that is technologically feasible, and the largest $\beta_{p}$ and smallest $q$ that are permitted for a satisfactory plasma equilibrium (e.g., $B_{p}<A$, $q \geq 2.5)$. The plasma aspect ratio $A$ is determined by (I) the sum 
of the thicknesses of the transformer core, the toroidal field coils, and the inner blanket-shield, and (II) the minimum plasma radius required for the desired power output or wall loading. . (In general, this latter requirement by itself will be such that the rather lenient conditions on $\tau_{E}$ and $\tau_{h}$ will be met.) Aspect ratios smaller than 3.5 are unlikely, because of dimension (I) and the maximum useful plasma radius (Fig.14), while aspect ratios greater than 7 are unlikely because of dimension (II).

\subsection{CHOICE OF INJECTION ENERGY}

This section considers the trade-offs between low and high injection energy, $w_{0}$. First, consider reactors with large power ratings ( $P_{\text {thermal }} \geq 100 \mathrm{MW}$ ). In general, $\overline{\mathrm{n}}_{\mathrm{e}}$ a must increase for reactors of increasing power output, so that the largest $W_{0}$ are required in order to insure penetration of the injected neutrals. But $Q$ decreases for $W_{0} \gtrsim 60 \mathrm{keV}$, and the neutron wall loading eventually decrease also in very large devices (cf. Fig. 14). For these reasons, there may be an economic penalty in going to a very large reactor (say, $\bar{n}_{e^{2}}>5 \times 10^{15} \mathrm{~cm}^{-2}$ ), which necessarily requires a large $W_{0}$.

In the case of reactors with small to moderate power ratings, there is always some leeway in choosing $w_{0}$ for tangential injection into a plasma of given radius, since acceptable trapping profiles are obtained for the range $0.4 a \leqslant \lambda_{t} \leqslant 1.2 a$ [12]. This margin is not as large as apparent, however, since the allowable $\mathrm{n}_{e}$ tends to decrease with increasing $\mathrm{w}_{\mathrm{O}}$. The advantages of operating at the maximum end of the $w_{0}$ range are the following: 
(1) The charge-exchange loss, $\mathrm{F}_{\mathbf{C x}}$, decreases with increasing $\mathrm{W}_{\mathrm{O}}$.

(2) If $Z_{\text {eff }}>1$, angular scattering is reduced at larger $\mathrm{w}_{\mathrm{O}}$.

(3) If a substantial cold-ion population cannot be avoided, at large $\mathrm{w}_{\mathrm{o}}$ one can take better advantage of target-plasma reactions, so that Q-values will not be as severely degraded.

(4). For the same injeclion powcr, less beam silurent is needed at lasyer $W_{0}$, which oould mean an amelioration of the difficult pumping problems in the beam ducts (if neutralization efficiency can be maintained).

An important figure-of-merit is the fractional burnup of tritium per pass. A large fractional burnup implies a small tritium throughput per unit thermal power production, so that the tritium inventory can be smaller, and the demands on the tritium processing system are reduced. It $\mathrm{f}_{B}$ is the fractional burnup for tritium (once-through), then

$$
\frac{{ }^{n} T}{T_{h^{\prime} l^{\prime}}} f_{R} E_{f}=P_{f}=Q P_{b}
$$

Using Eq. (14) and $\tau_{\mathrm{hT}}=1.5 \tau_{\mathrm{hD}}$, we have

$$
f_{B}=\frac{Q W_{U}}{E_{E}}\left(1+\frac{\tau_{h T}}{\tau_{h D}}\right)=2.5 \frac{Q W_{O}}{E_{f}}
$$


Figure 15 shows $f_{B}$ as a function of $W_{O}$ and $T_{e}$. At constant $W_{O^{\prime}}$ the increase in $f_{B}$ with $T_{e}$ is due to the increase in fast-ion slowing-down time (and concomitant increase in Q). At a given $\mathrm{T}_{\mathrm{e}^{\prime}}, \mathrm{f}_{\mathrm{B}}$ increases with $\mathrm{W}_{\mathrm{O}^{\prime}}$, reflecting (1) a somewhat longer $\tau_{h}$ for more energetic ions, and (2) a larger average ov over the lifetime of these ions. Furthermore, with increasing $w_{O}$, a given $\mathrm{T}_{\mathrm{e}}$ is attained at a smaller value of $\mathrm{n}_{\mathrm{e}} \tau_{\mathrm{E}}$ (cf. Fig. 5).

Most of the above considerations would seem to indicate that in reactors of modest size, the energy range 50 to $80 \mathrm{keV}$ is generally to be preferred to the range 30 to $50 \mathrm{keV}$. But in the end, the choice of injection energy may very well depend on the efficiency of neutral beam production, which tends to be larger at lower energies. Overall efficiencies of $60 \%$ (busbarto-beam) have been achieved for $D^{\circ}$ beams at $40 \mathrm{keV}$ (although present-day beams contain appreciable quantities of $\mathrm{D}_{2}^{\circ}$ and $\mathrm{D}_{3}^{\circ}$ ). While the neutralization efficiency of $\mathrm{D}^{+}$decreases markedly for $W_{0} \gtrsim 50 \mathrm{keV}$, satisfactory overall efficiency can in principle be maintained even for $w_{0} \gg 50 \mathrm{keV}$ by the use of direct conversion of unneutralized ions, but with the penalty of increased unit capital cost compared with that for low-energy injection.

\subsection{RADIATION TEST FACILITY}

The behavior of wall materials and blankets subject to intense bombardment of $14-\mathrm{MeV}$ neutrons must be investigated in the course of developing fusion reactors. As noted in Sec. 4.1, the neutron wall loading in a CBT reactor is unlikely to exceed $0.5 \mathrm{MW} / \mathrm{m}^{2}$, so that a CBT plasma cannot profitably be employed to study neutron-induced bulk-radiation effects, which require wall 
loadings in the range $1 \mathrm{MW} / \mathrm{m}^{2}$ and above [22]. (A target-plasma reactor has been proposed for this purpose [23].) On the other hand, the CBT does seem suitable for studies of neutron-induced radiation damage to surfaces, simultaneously with studies of the effects of energetic particle and photon bombardment.

For this purpose one requires a neutron flux of at least $3 \times 10^{12} \mathrm{n} / \mathrm{cm}^{2} / \mathrm{s}\left(0.07 \mathrm{MW} / \mathrm{m}^{2}\right)$, with a minimum fluence for a given test sample in the range $10^{19}-10^{20} \mathrm{n} / \mathrm{cm}^{2}$ [22]. The neutron source must be capable of a high duty factor, to meet Ehls Iluence requirement. It is worth emphasizing that the large test area inherent in any tokamak device insures that a large number of surface radiation experiments can be simultaneously accommodated.

The special requirements of a test reactor for surface radiation effects are (1) time-averaged neutron flux $\geq 3 \times 10^{12}$ $\mathrm{n} / \mathrm{cm}^{2} / \mathrm{s} ;$ (2) as small a total power input as possible; (3) $Q \geqslant \frac{1}{2}$, in order to minimize the capital cost of the beam injectors, the number of beam lines, and the circulating power; (4) ease of access for replacement of test sections. The test reactor would be driven by an external power source, and if copper TF coils are used, these would in fact account for most of the power loss. No blanket is required, allivuyli suitable means for removing the thermal puwer yenerated (injectcd power and fusion power) must be provided. Tritium must be supplied from an external source.

Illustrative plasma parameters are presented in Table I. The modest elongation of the plasma cross-section is compatible with the provision of a poloidal divertor. Water-cooled-copper TF coils are specified, since perhaps only these are technologically feasible for a near-term toroidal device, and since 
replacement of test specimens and diagnostics is facilitated with room-temperature coils. While an injection energy of $40 \mathrm{keV}$ would be adequate, $w_{0}=60 \mathrm{keV}$ is specified for the reasons discussed in Sec. 4.2. An ideal Q larger than unity is probably required, because of the deleterious effects of charge-exchange losses, impurities, and excessive population of cold ions. The time-averaged neutron flux $(50 \%$ duty factor $)$ is $0.10 \mathrm{MW} / \mathrm{M}^{2}$, and the useful test area (on the outer part of the torus vacuum vessel) is $25 \mathrm{~m}^{2}$.

Long-pulse, high-duty-factor, neutral beam operation is essential for this and other CBT reactor applications. Present 40-keV injectors operate with $0.3-s$ pulses and duty factors of 15\% [24]. It appears that steady-state operation should be feasible with large-area beams, and a 50-keV, 50-A, 2-s source is presently under development [24].

\subsection{FUSION-FISSION HYBRID REACTORS}

The 14-MeV neutrons from the DT reaction can be used to breed fissile material $\left({ }^{233} \mathrm{U},{ }^{239} \mathrm{Pu}\right)$ in a fertile blanket $\left({ }^{232} \mathrm{Th}\right.$, $\left.{ }^{238} \mathrm{U}\right)$ surrounding the fusion plasma, and the neutron energy can be multiplied by fission reactions in this blanket [2]. In the following, we use the term hybrid reactor for any fusion-driven device having a blanket containing fertile material. The hybrid can be an economic power producer even when $Q$ of the fusion core is smaller than unity, because of the large energy gain $(\geq 10)$ attainable in the blanket [2], Alternatively, the fissile products may be removed and utilized in thermal fission reactors, a small fraction of the electrical output of which may be diverted 
to make up the power deficit of the fusion reactor (a "symbiotic" system [2]). It was shown in Ref. [3] that for a beam-driven fusion reactor with negligible fission power produced in the blanket, $Q \geq 0.75$ is needed for satisfactory overall power balance of the symbiotic system. (Defrayment of the capital cost of the fusion reactor requires another condition, however.)

Whether or not symbiotic operation is employed, the special requirements for the plasma of an economic hybrid reactor are (1) large power output and large duty factor, so that the ammul production of tissile material and energy provide a sufficient return on the total capital investment; (2) large wall loading, to maximize the cost effectiveness of the blanket; (3) $Q \sim 1$, or smaller if the blanket has a large power multiplicalion. In addition to production of fissile material, the blanket must have a tritium breeding ratio of at least unity. If the DT neutron energy is not moderated, then a total thickness of $1.3 \mathrm{~m}$ for the blanket and shield is adequate.

The preferred plasma operating point is the large-radius end of the plateau of maximum neutron wall loading (Fig. 14), in order to meet conditions (1) and (2) above. The reduction in $Q$ at large $W_{0}$ can be tolerated, and moderate ' ${ }^{\prime}$ ' is satisfactory. Illustrative plasma parameters are given in Táble I. n 30-om scrape-nff layer. is provided between the plasma edge and the vacuum wall. In order to attain the highest possible toroidal field on axis, $\mathrm{Nb}_{3} \mathrm{Sn}$ coils are specified. The injection energy of $10.0 \mathrm{keV}$ affords adequate penetration of the plasma, whose radius is chosen to provide the largest possible wall loading for the allowable plasma pressure 
$\left(\beta_{p}=2 / 3 A\right.$ at $\left.q=3\right)$. The transformer core is capable of 18 V-sec, which is sufficient to drive 2.6-MA pulses up to $50 \mathrm{~s}$ duration; much longer pulses are possible with the same core, if the plasma current can be maintained by the beams [17]. The neutron power output of $103 \mathrm{MW}$ is convenient for electrical generating plants of moderate size. For fast-fission blankets such as considered in [25], and $75 \%$ duty factor, the production rates (net) of fissile material and electrical power would be in the range 2-3 $\mathrm{kg} / \mathrm{day}$ and 150-900 $\mathrm{MW}$, respectively, with a tritium breeding ratio of at least 1.05 .

\subsection{TRITIUM PRODUCTION}

Tritium is presently used as a reactant in thermonuclear explosives, and for the production of ${ }^{3}$ He by beta-decay. If the controlled fusion program continues to develop, one may expect large amounts of tritium to be required for fusion test reactors, and eventually for the start-up of a fusion power economy. In the case of a system of hybrid reactors, it may turn out to be most convenient to relegate the function of breeding tritium to separate reactors, in order, to better utilize the hybrid neutrons for fissile breeding.

A DT fusion reactor can produce considerable amounts of tritium for sale, because with appropriate neutron-multiplying materials in the blanket, such as sodium or beryllium, a tritium breeding ratio of 2.0 is attainable [26], with a doubling time of the order of several months or less. If tritium production is the principal purpose of the reactor, economic viability demands large power output per unit.size, large wall loading, and a large duty factor. The reactor should also have overall electrical 
energy break-even - the high cost of externally-supplied electricity would probably make tritium production prohibitively expensive. With superconducting $\mathrm{TF}$ coils and efficiently generated neutral beams, $Q \geq 2.5$ is required, considering that each neutron may generate up to an extra $10 \mathrm{MeV}$ in an optimized blanket [26]. Illustrative plasma parameters for a CBT "tritium factory" are shown in Table $I$. Attaining $Q>2$ demands a large $\mathrm{T}_{\mathrm{e}}$, and correspondingly large $\mathrm{n}_{e^{\tau} \mathrm{E}}$, so that a larger plasma radius is spcoified than in the hybrid.case. The 125-MW neutron power is near the maximum one can reasonably produce in a CBT reactor with $\mathrm{w}_{\mathrm{O}} \tilde{<} 100 \mathrm{keV}$. The annual net tritium production for operation at $80 \%$ duty factor is $7.0 \mathrm{~kg}$. 
Table I

ILLUSTRATIVE PARAMETERS FOR COUNTERSTREAMING-ION TOKAMAK REACTORS

\begin{tabular}{|c|c|c|c|}
\hline . & $\begin{array}{l}\text { Radiation } \\
\text { Test } \\
\text { Facility }\end{array}$ & $\begin{array}{l}\text { Hybrid } \\
\text { Reactor }\end{array}$ & $\begin{array}{l}\text { Tritium } \\
\text { Producer }\end{array}$ \\
\hline $\mathrm{R}_{\mathrm{O}} \quad(\mathrm{m})$ & 2.45 & 4.05 & 4.20 \\
\hline a $\quad(m)$ & 0.50 & 0.75 & $0: 90$ \\
\hline A & 4.9 & 5.4 & 4.7 \\
\hline Vertical elongation & 1.25 & 1.25 & 1.25 \\
\hline Midplane wall radius (m) : & 0.75 & 1.05 & 1.20 \\
\hline $\mathrm{TF}$ coil material & $\mathrm{Cu}$ & $\mathrm{Nb}_{3} \mathrm{Sn}$ & $\mathrm{Nb}_{3} \mathrm{Sn}$ \\
\hline$B_{t}$ on axis (kG) & $40 *$ & 55 & 53 \\
\hline$B_{t}$ at $\operatorname{coil} \quad(k G)$ & $82 *$ & 130 & 130 \\
\hline Blanket/shield thickness (m) & 0.5 & -1.3 & 1.3 \\
\hline$I_{p} \quad(M A)$ & 1.4 & 2.6 & 3.5 \\
\hline q & 3.0 & 3.0 & 3.0 \\
\hline $\bar{n}_{e}\left(\mathrm{~cm}^{-3}\right)$ & $4 \cdot 3 \times 10^{13}$ & $4.8 \times 10^{13}$ & $4.3 \times 10^{13}$ \\
\hline$\overline{\mathrm{T}}_{\mathrm{e}} \quad(\mathrm{keV})$ & 4.0 & 5.0 & 8.0 \\
\hline $\bar{n}_{e^{\tau} E} \quad\left(\mathrm{~cm}^{-3} \mathrm{~s}\right)$ & $2.1 \times 10^{12}$ & $2 \cdot 3 \times 10^{12}$ & $6.5 \times 10^{12}$ \\
\hline$w_{o} \quad(\mathrm{keV})$ & 60 & 100 & 100 \\
\hline$\lambda_{t} / a$ & 0.92 & 0.75 & 0.72 \\
\hline Injection power (MW) & 19 & 97 & 68 \\
\hline$B_{p}$ & 3.3 & 3.6 & 3.1 \\
\hline$Q(i d e a l)$ & 1.32 & 1.33 & 2.3 \\
\hline$P_{f}\left(w / \mathrm{cm}^{3}\right)$ & 1.28 & 1.81 & 1.43 \\
\hline Total neutron flux $(\mathrm{n} / \mathrm{s})$ & $8.9 \times 10^{18}$ & $4.6 \times 10^{19}$ & $5.5 \times 10^{19}$ \\
\hline Neutron wall loading $\left(\mathrm{MW} / \mathrm{m}^{2}\right)$ & 0.20 & 0.45 & 0.44 \\
\hline Total neutron power (MW) & 20 & 103 & 125 \\
\hline
\end{tabular}

$\star$ duty factor $=508$ 


\section{CONCLUSIONS}

This paper has considered those properties of a beam-driven counterstreaming-ion tokamak plasma (CBT) that are most relevant for application to DT fusion reactor design. By postulating that in steady-state there exists an equipartition of energy between the directed ion motion and the total plasma thermal motion, ion velocity distributions and plasma properties are derived that are in good agreement with known Fokker-Planck results. Fusion reactivity, power gain $Q$, and power density $\mathrm{P}_{f}$ have been calculated for wide ranges of injection energy and electron temperature, and the results demonstrate a trade-off between $Q$ and $P_{f}$.

The principal practical problem in implementing a counterstreaming-ion plasma in a tokamak is the need to minimize the cold-ion population. Decelerated ions $\left(W<2 T_{e}\right)$ are removed chiefly by instability-induced diffusion, but also by chargeexchange on injected neutrals, and by diffusion induced by magnetic field ripple. A poloidal magnetic divertor is probably required to minimize ion recycling, to remove impurities from the torus, and to reduce bombardment of the wall by ions leaving the discharge. The trapping process of injected neutrals results in less than $10 \%$ energy loss by charge exchange. Impurities reduce $Q$ mainly by enhancement of angular scattering, thus undermining the advantage of head-on nuclear collisions.

The counterstreaming-ion system seems advantageous for a low-power, high-duty-factor, Q $: 1$ neutron source. Injection energies are modest $(40-60 \mathrm{keV})$; the electron energy confinement 
time can be small (e.g., $\mathrm{n}_{\mathrm{e}^{\tau} \mathrm{E}} \approx 2 \times 10^{12}$ at $\mathrm{T}_{\mathrm{e}} \approx 3.5 \mathrm{keV}$ ); refueling is accomplished entirely by the injected beams; and the plasma current can be maintained by the beams. To insure adequate penetration by neutral beams, the maximum useful size is apparently significantly smaller than that of a TCT (target-plasma) reactor, and many times smaller than that of a thermonuclear reactor.

Plasma parameters were considered for three applications of CBT-generated neutrons: a 20 MW (neutron power) surface radiation effects reactor, with a time-averaged neutron flux of $5 \times 10^{12} \mathrm{n} / \mathrm{cm}^{2} / \mathrm{sec}$; a $100 \mathrm{MW}$ fusion-fission hybrid reactor; and a $125 \mathrm{MW}$ tritium producer. The lenient requirements on beam voltage and $n_{e} \tau_{E}$ would seem to make these reactor applications feasible in the near future.

\section{ACKNOWLEDGMENTS}

The author acknowledges many useful discussions with Dr. R. M. Kulsrud and Mr. Y. C. Sun concerning their FokkerPlanck results. This work was supported by the United States Energy Research and Development Administration Contract $E(11-1)-3073$. 
REFERENCES

[1] KULSRUD, R. M., JASSBY, D. L., Princeton Plasma Physics Laboratory MATT-1114 (1975); see also JASSBY, D. L., KULSRUD, R. M., Bull. Am. Phys. Soc. 20 (1975) 658 .

[2] LEONARD, B. R., Jr., Nuclear Technology 20 (1973) 161; see also LIDSKY, L. M.', Nucl. Fusion $\underline{15}$ (1975) 151.

131 JASSBY, D. L., Princeton Plasma Physics Laboratory Report MATT-1072 (1974), to be published in Nuclear Fusion.

[4] KULSRUD, R. M., SUN, Y. C., unpublished.

[5] PERKINS, F. W., Jr., unpublïshed.

[6] BOL, K., et al., in Plasma Physics and Controlled Nuclear Fusion Research (Proc. 5th Int. Conf., Tokyo, 1974), paper CN-33/A4-1 (to be published); see also BERRY, L.A., et al., ibid., paper $\mathrm{CN}-33 / \mathrm{A} 5-2$.

[7] BERK, H. L., et al., Princeton Plasma Physics Laboratory Report MATT-1127'(1975).

[8] DUANE, B. H., Battelle Pacific Northwest Laboratories Report BNWL-1685 (1972).

[9] BERK, H. L., et al., in Plasma Physics and Controlled Nuclear Fusion Research (Proc. 5th Int. Conf., Tokyo, 1974), paper $\mathrm{CN}-33 / \mathrm{G} 2-3$ (to be published).

[10] LOVELACE, R. V., Cornell Univ. Lab. of Plasma Studies Report No. 162 (1975).

[11] RIVIERE, A. C.,. Nucl. Fusion 11 (1971) 363.

[12] ROME, J. A., CALLEN, J. D., CLARKE, J. F., Nucl. Fusion 14 (1974) 141 . 
[13] MEADE, D. M., et al., in Plasma Physics and Controlled Nuclear Fusion Research (Proc. 5th Int. Conf., Tokyo; 1974), paper $\mathrm{CN}-33 / \mathrm{Al5}-4$ (to be published).

[14] KADOMTSEV, B. B., POGUTSE, O. P., Zh. Eksp. Teor. Fiz. 51 (1966) 1734

[15] STRINGER, T. E., Nucl. Fusion 12 (1972) 689.

[16] BOOZER, A. H., private communication:

[17] JASSBY, D. L., unpublished.

[18] OHKAWA, T., Nucl. Fusion 10 (1970) 185.

[19]. GIRARD, J. P., MARTY, D., MORIETTE, P., in Plasma Physics and Controlled Nuclear Fusion Research (Proc. 5th Int.

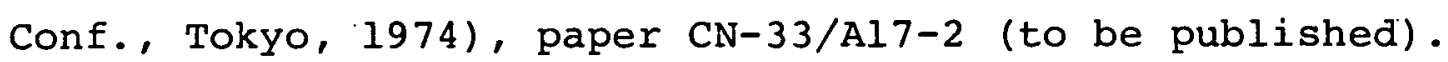

[20] The Alcator Group, Bull. Am. Phys. Soc. 20 (1974) 657.

[21] STOTT, P.. E., DAUGHNEY, C. C., ELLIS, R. A., Princeton Plasma Physics Laboratory Report MATT-1111 (1975) •

[22] PERSIANI, P. J., Proc. First Topical Meeting on the Technology of Controlled Nuclear Fusion (San Diego, 1974), Vol. I, p. 283 .

[23] CONN, R. W., JASSBY, D. L., Univ. of Wisconsin Report FDM-119 (1975).

[24] Proc. Second Symposium on Ion Sources and Formation of Ion Beams (Berkeley, Calif., October 1974), papers II-8, VI-9, VI-10. 
[25] LEE, J. D., Proc. 7th Intersociety Energy Conversion

Engineering Conf. (American Chemical Society, 1972), p. 1294;

see also LEE, J. D., Proc. First Topical Meeting on the

Technology of Controlled Nuclear Fusion (San Diego, 1974),

Vol. 1, p. 223; MANISCALCO, J. A., and WOOD, L. L., Trans.

Amer. Nucl. Soc., 1974 Winter Meeting, p. 6.

[26] LEE, J. D., Symposium on Thermonuclear Fusion Reactor Design, Lubbock, Texas, June 1970, p. 98. 


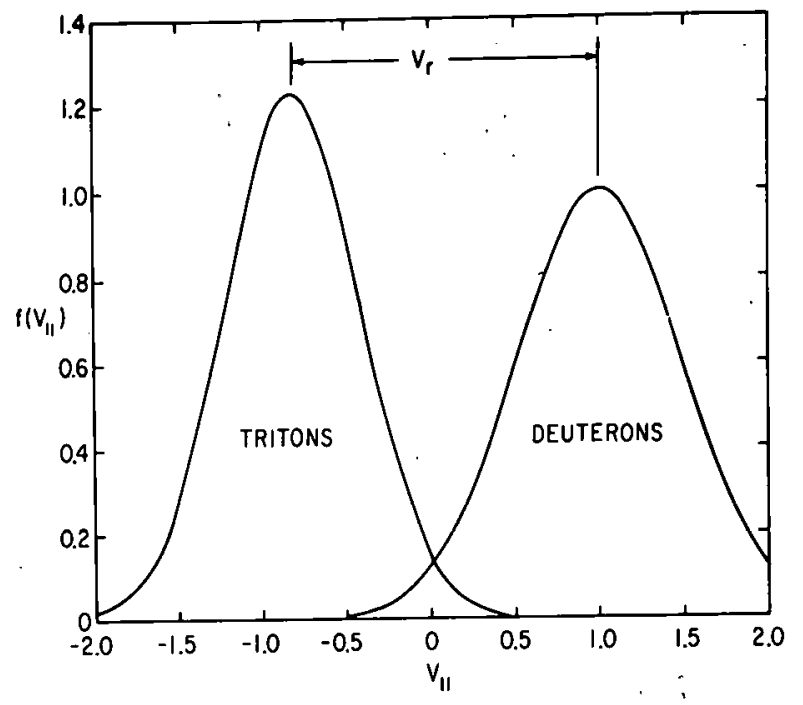

753457

Fig. 1. Counterstreaming-ion velocity distributions parallel to the toroidal magnetic field. The two distributions have the same density, temperature; and total energy.

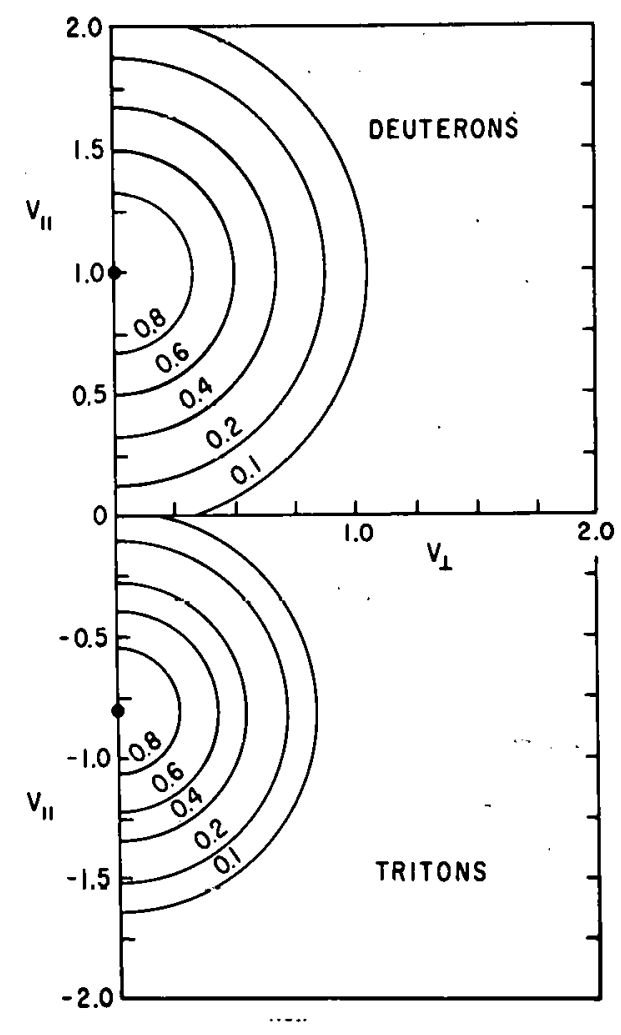

Fig. 2. Contours of displaced-Maxwellian velocity distributions of counterstreaming $D$ and $T$ ions. The large dots indicate $f(v)=1.0$. The two distributions have the same temperature and average energy. 

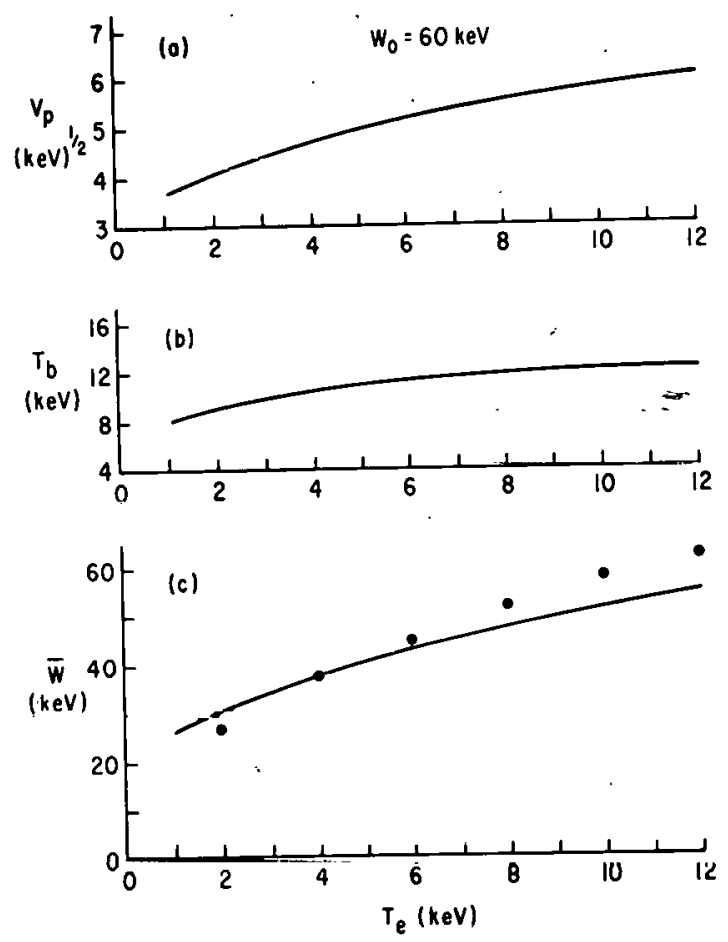

753455

Fig. 3. (a) Mean parallel velocity, (b) temperature, and (c) average energy of the displaced-Maxwellian deuteron velocity distribution in a counterstreaming-ion plasma with injection energy of $60 \mathrm{keV}$. The large dots in (c) are the results of a Fokker-Planck calculation in Ref. [4].

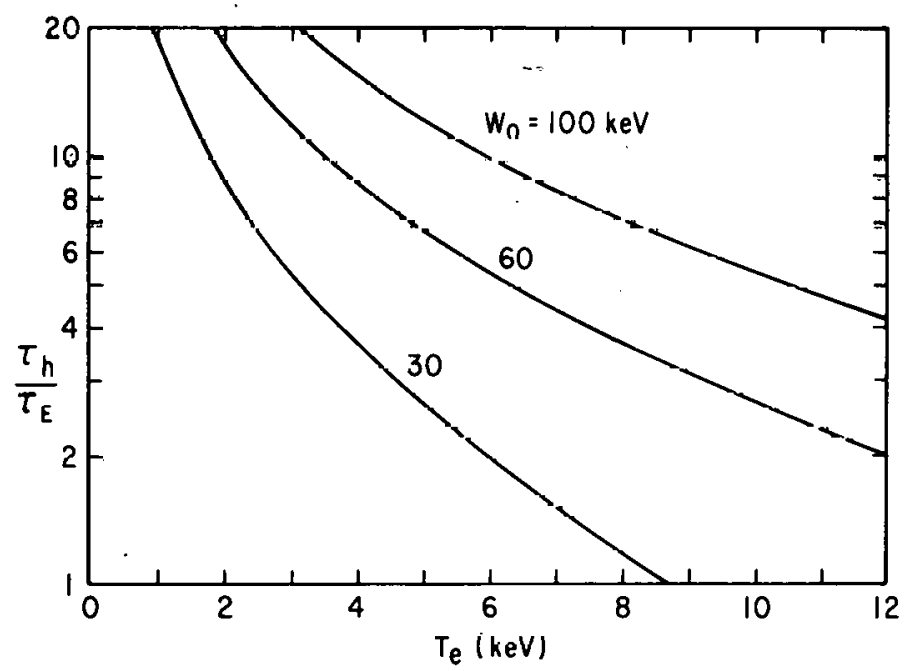

753449

Fig. 4. Ratio of ion lifetime to electron energy confinement time in a counterstreaming-ion plasma as a function of $\mathrm{T}_{e}$, for various injection energies $\mathrm{w}_{\mathrm{o}}$. 


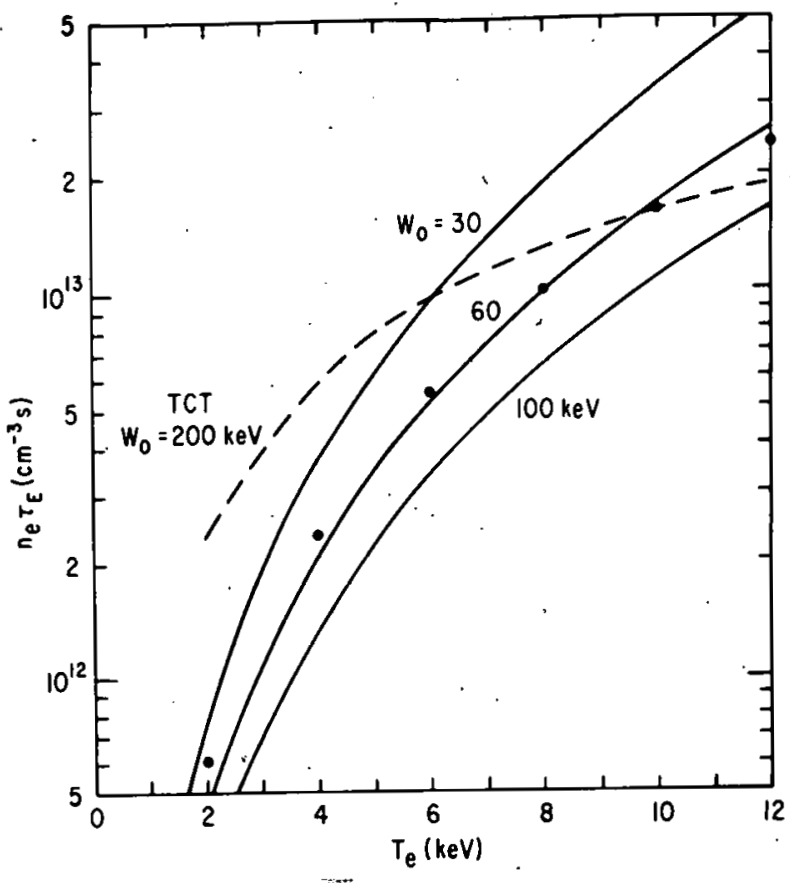

753461

Fig. 5. Dependence of eliectron energy confinement time on $\mathrm{W}_{\mathrm{O}}$ and $\mathrm{T}_{\mathrm{e}}$. The large dots are the results of a Fokker-Planck calculation for $\mathrm{W}=60 \mathrm{keV}$, in Refs. [1,4]. The TCT case is for maximum fusion power density [3].

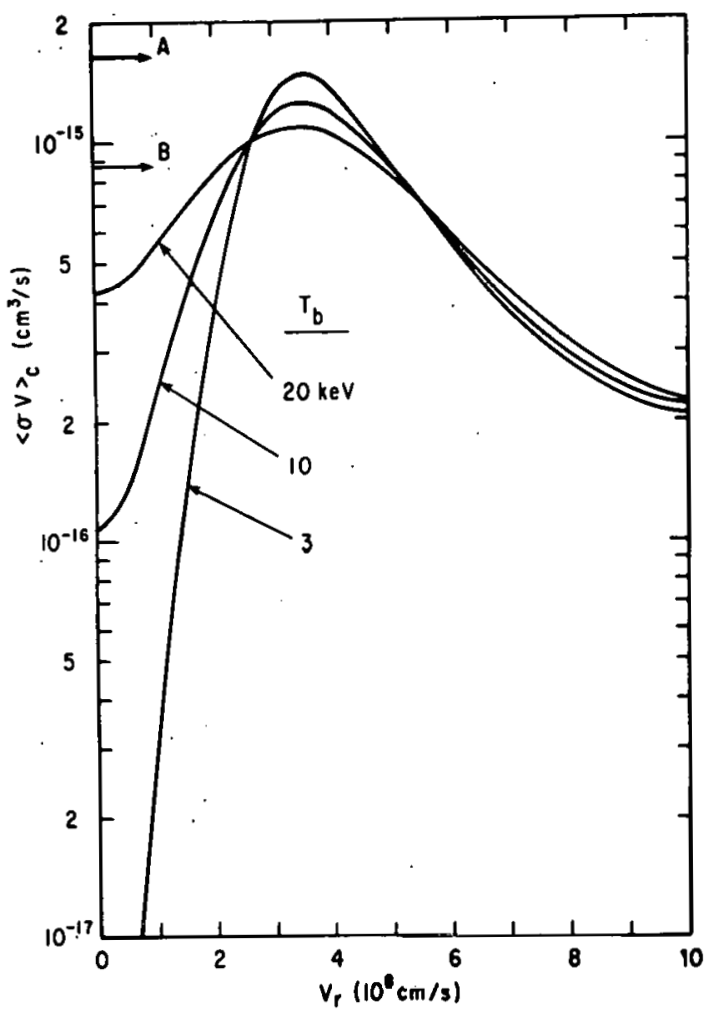

Fig. 6. Fusion reactivity of $\mathrm{D}$ and $\mathrm{T}$ displaced-Maxwellian distributions, each of temperature $T_{b}$, with relative displacement velocity $v_{r}$. The maximum reactivity of a DT beam-target system $\left(W_{\text {beam }}=125 \mathrm{keV}\right)$ is denoted by $A$. The maximum reactivity of a thermonuclear DT plasma $\left(T_{i}=60 \mathrm{keV}\right)$ is denoted by $\mathrm{B}$. 


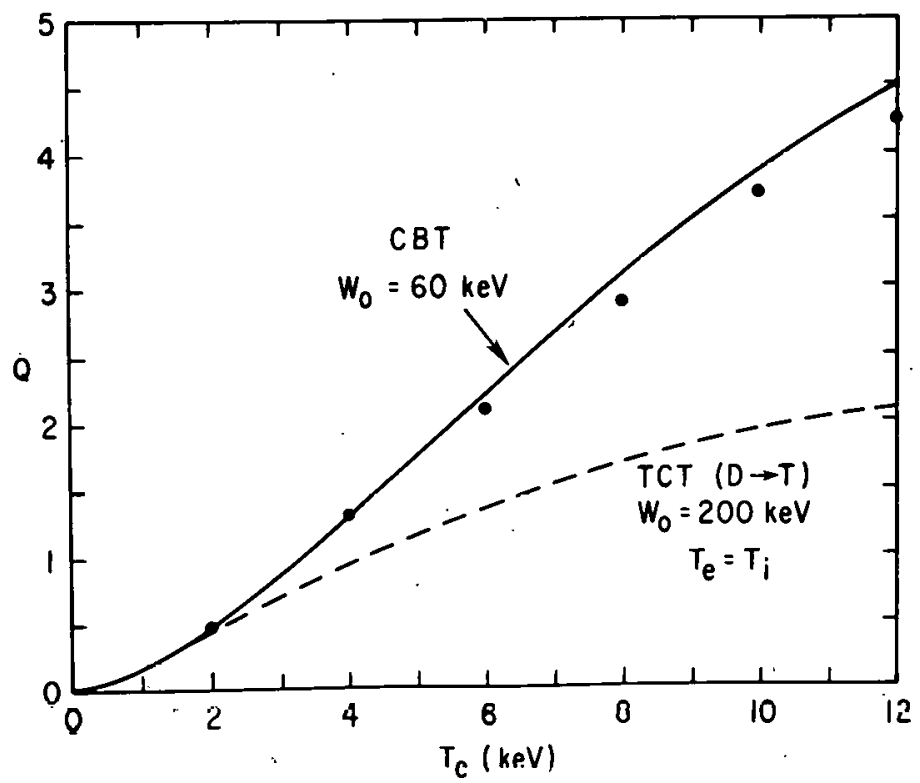

753462

Fig. 7. Fusion power gain Q for steady-state counterstreamingion operation in DT, taking $17.6 \mathrm{MeV}$ per reaction. The large dots are the results of a Fokker-Planck calculation in Refs. $[1,4]$.

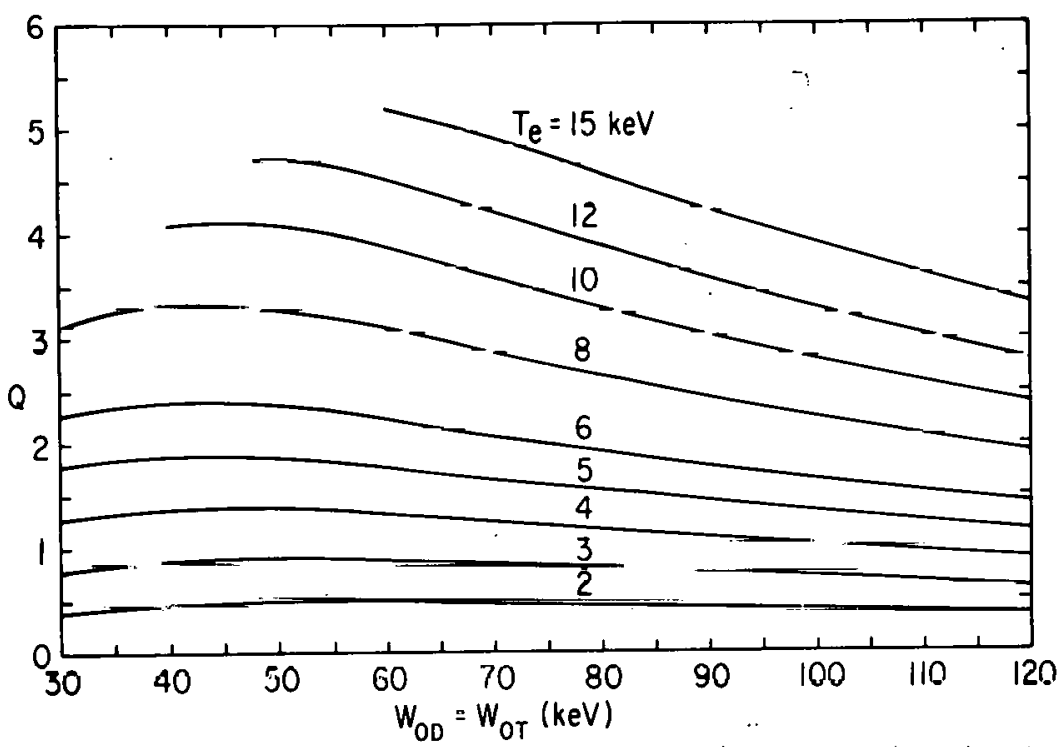

753456

Fig. 8. Fusion power gain $Q$ for steady-state counterstreamingion operation in $\mathrm{DT}$, as a function of injection energy and $\mathrm{T}_{\mathrm{e}}$.
$17.6 \mathrm{MeV}$ per reaction. 


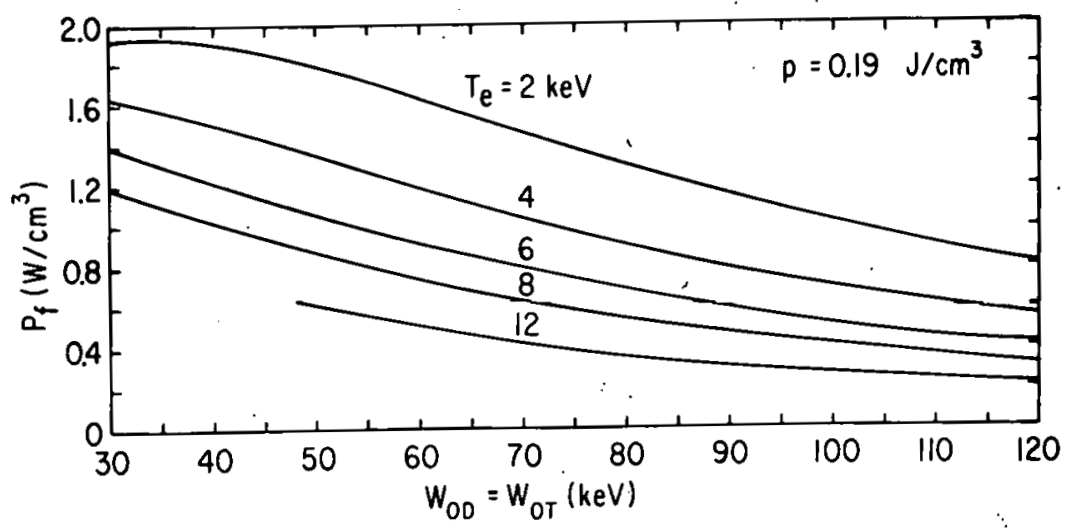

.753448

Fig. 9. Fusion power density $P_{f}$ for counterstreaming-ion operation in DT, as a function of injection energy and $\mathrm{T}_{e}$. Total plasma pressure $=0.19 \mathrm{~J} / \mathrm{cm}^{3}$, corresponding to tokamak parameters $B_{t}=50 \mathrm{kG}, A=5.0, B_{p}=3.0, q=2.5$.

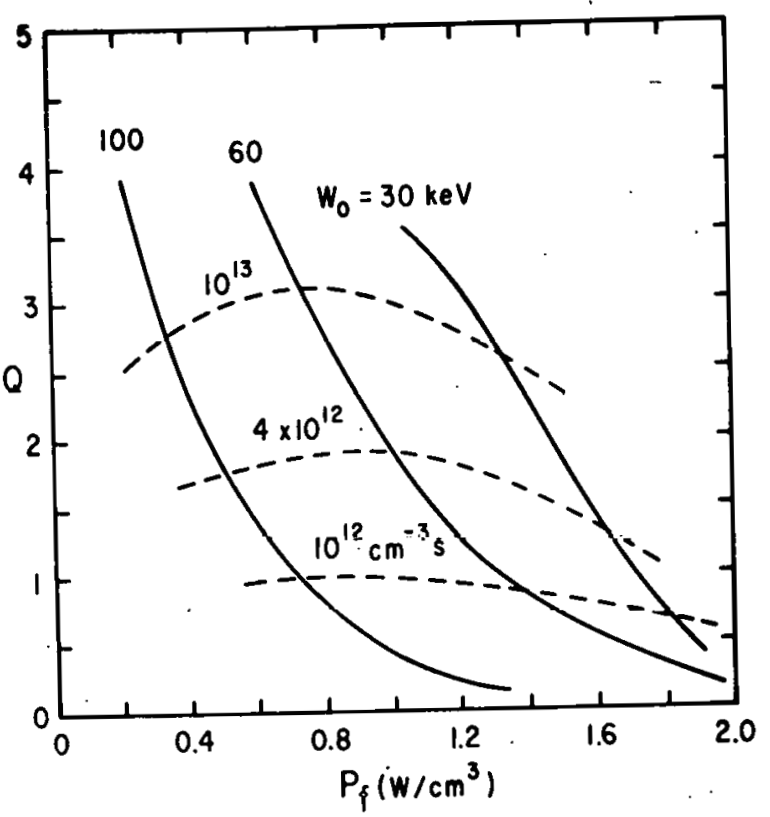

753459

Fig. 10. Q versus $P_{f}$ for a counterstrëaming-ion.DT plasma. The solid curves are contours of constant injection energy, and the dashed curves are contours of constant $n_{e^{\tau}} \cdot$ Total plasma pressure $=0.19 \mathrm{~J} / \mathrm{cm}^{3}$. 


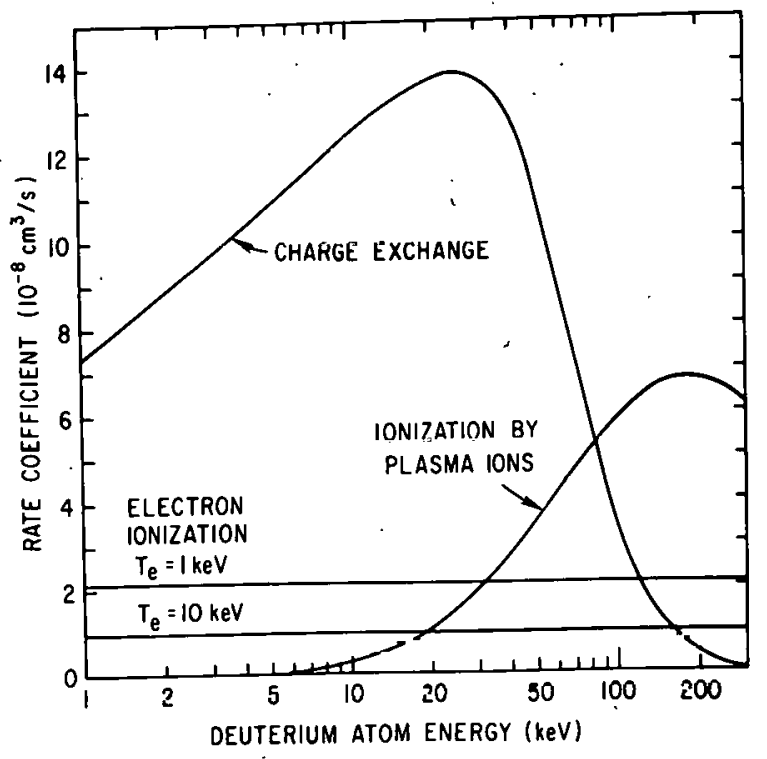

753460

Fig. il. Rate coefficients for charge-exchange, ionization by plasma ions, and electron ionization for a deuterium atom in a hydrogenic plasma.
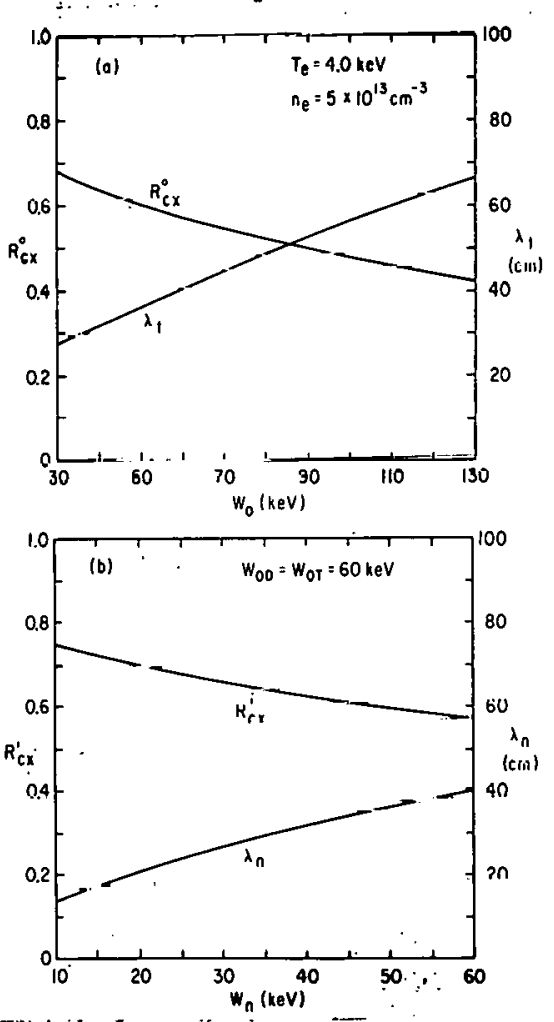

753453

Fig. 12. (a) Trapping length $\lambda_{t}$ of deuterium atoms of energy $\mathrm{w}_{0}$ injected into a counterstreaming-ion plasma formed by injection at $W_{O}$. $R_{C x}^{O}$ is the fraction of atoms trapped by charge exchange. (b) Mean-free-path $\lambda_{n}$ for charge exchange or ionization of a deuterium neutral of energy $W_{n}$ in a counterstreaming-ion plasma formed by injection at $60 \mathrm{keV}$. $R_{C x}^{\prime}$ is the relative probability of a charge-exchange collision. 


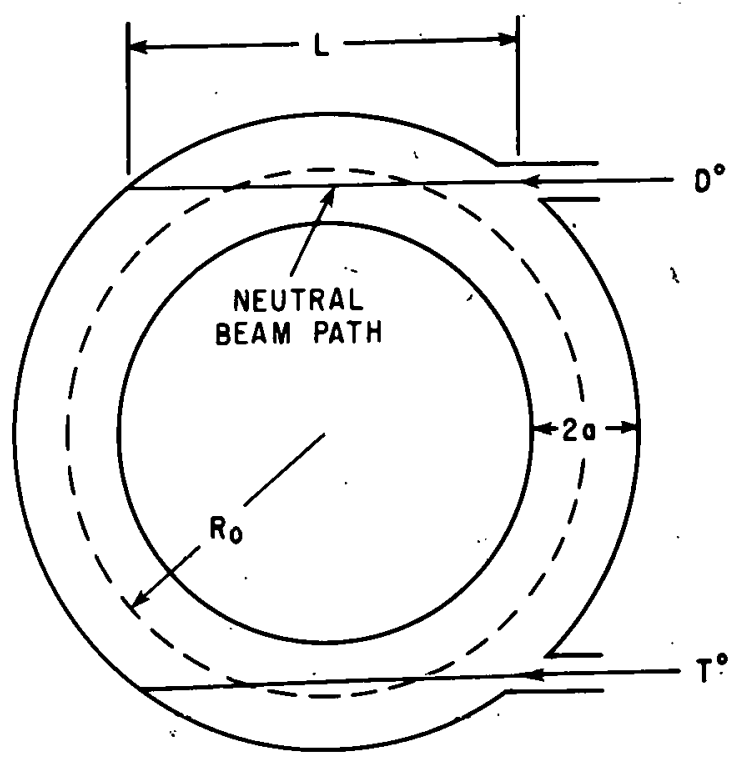

753452

Fig. 13. Plan view of geometry of tangential neutral-beam injection into a torus.

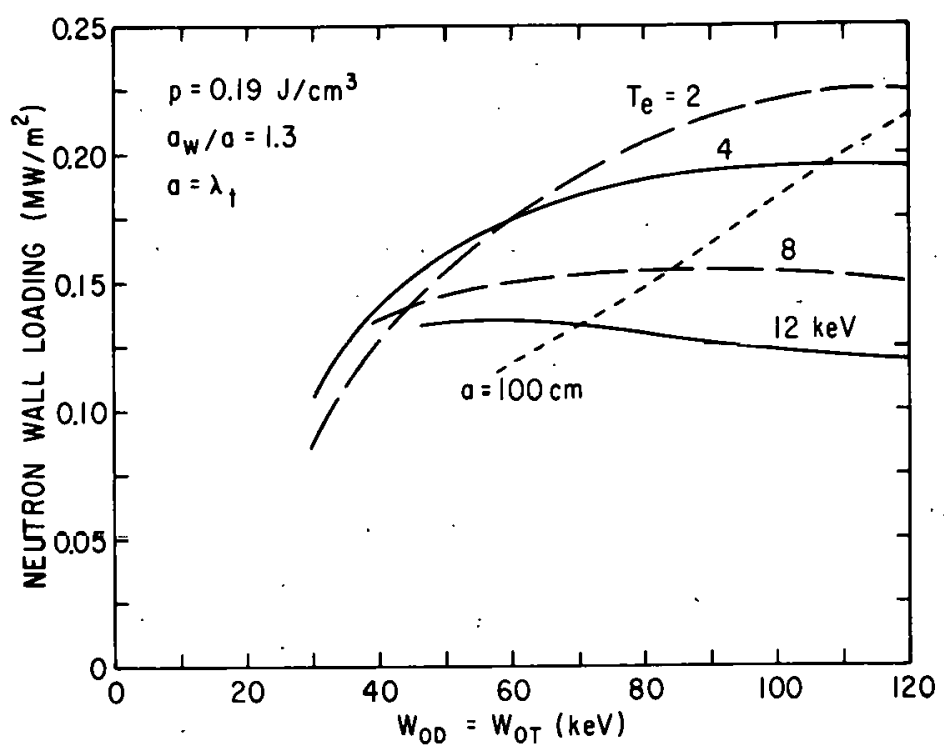

753454

Fig. 14. Neutron wall loading in a counterstreaming-ion tokamak reactor. Plasma pressure $=0.19 \mathrm{~J} / \mathrm{cm}^{3}$, and plasma radius = neutral-beam trapping length. Reactors to the left of the dotted line have plasma radius $<100 \mathrm{~cm}$. 


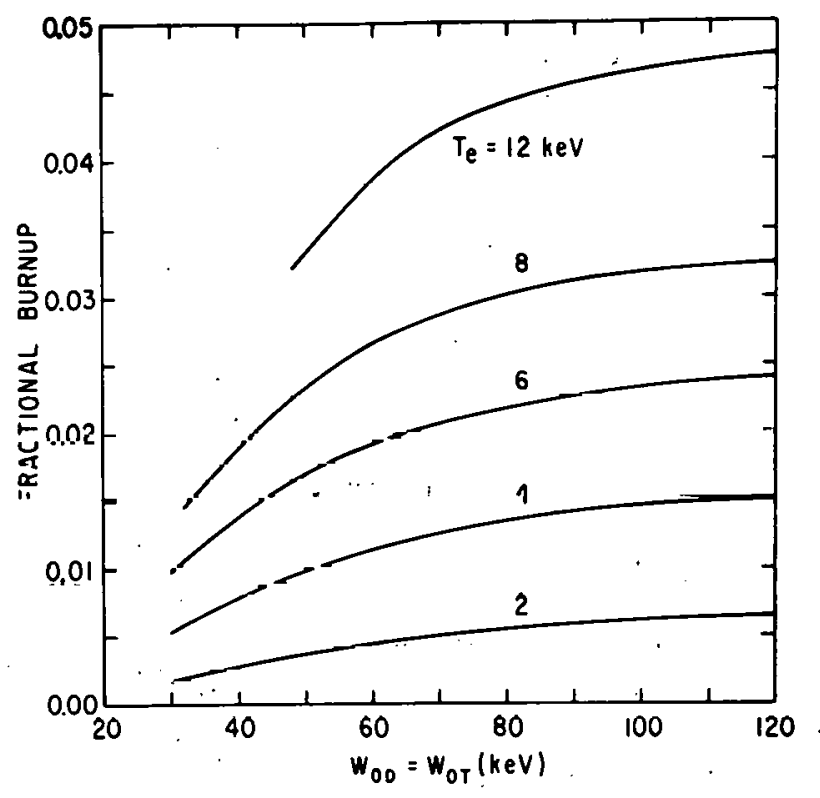

753458

Fig. 15. Fractional burnup of tritons per pass in a counterstreaming-ion DT reactor, as a function of $\mathrm{T}_{\mathrm{e}}$ and injection energy $W_{O D}=W_{O T}$. 


\section{NOTICE}

This report was prepared as an account of work sponsored by the United States Government. Neither the United States nor the United States Atomic Energy Commission, nor any of their employees, nor any of their contractors, subcontractors, or their employees, makes any warranty, express or implied, or assumes any legal liability or responsibility for the accuracy, completeness or usefulness of any information, apparatus, product or process disclosed, or represents that its use would not infringe privately owned rights. 